\title{
The Active FaUlts of Eurasia Database
}

\author{
D. M. Bachmanov1, A. I. Kozhurin'1, 2, V. G. Trifonov ${ }^{1}$ \\ ${ }^{1}$ Geological Institute of RAS, Moscow, Russia \\ ${ }^{2}$ Institute of Volcanology and Seismology, Far East Branch of RAS, Petropavlovsk-Kamchatsky, Russia
}

\begin{abstract}
This paper describes the technique used to create and maintain the Active Faults of Eurasia Database (AFED) based on the uniform format that ensures integrating the materials accumulated by many researchers, including the authors of the AFED. The AFED includes the data on more than 20 thousand objects: faults, fault zones and associated structural forms that show the signs of latest displacements in the Late Pleistocene and Holocene. The geographical coordinates are given for each object. The AFED scale is 1:500000; the demonstration scale is 1:1000000. For each object, the AFED shows two kinds of characteristics: justification attributes, and estimated attributes. The justification attributes inform the AFED user about an object: the object's name; morphology; kinematics; the amplitudes of displacement for different periods of time; displacement rates estimated from the amplitudes; the age of the latest recorded signs of activity, seismicity and paleoseismicity; the relationship of the given objects with the parameters of crustal earthquakes; etc. The sources of information are listed in the AFED appendix. The estimated attributes are represented by the system of indices reflecting the fault kinematics according to the classification of the faults by types, as accepted in structural geology, and includes three ranks of the Late Quaternary movements and four degrees of reliability of identifying the structures as active ones. With reference to the indices, the objects can be compared with each other, considering any of the attributes, or with any other digitized information. The comparison can be performed by any GIS software. The AFED is an efficient tool for obtaining the information on the faults and solving general problems, such as thematic mapping, determining the parameters of modern geodynamic processes, estimating seismic and other geodynamic hazards, identifying the tectonic development trends in the Pliocene-Quaternary stage of the Earth's development, etc. The Active Faults of Eurasia Database is created in the format providing for inputs of new information, as well the database updating and revision.
\end{abstract}

Key words: active fault; database creation and maintenance

\section{RESEARCH ARTICLE}

Recommended by E.V. Sklyarov
Received: August 15, 2017

Revised: September 12, 2017

Accepted: November 13, 2017

For citation: Bachmanov D.M., Kozhurin A.I., Trifonov V.G., 2017. The Active Faults of Eurasia Database. Geodynamics \& Tectonophysics 8 (4), 711-736. doi:10.5800/GT-2017-8-4-0314.

Для цитирования: Бачманов Д.М., Кожурин А.И., Трифонов В.Г. База данных активных разломов Евразии // Геодинамика и тектонофизика. 2017. Т. 8. № 4. C. 711-736. doi:10.5800/GT-2017-8-4-0314. 


\title{
БАЗА ДАННЫХ АКТИВНЫХ РАЗЛОМОВ ЕВРАЗИИ
}

\author{
Д. М. Бачманов ${ }^{1}$, А. И. Кожурин ${ }^{1,2}$, В. Г. Трифонов 1 \\ ${ }^{1}$ Геологический институт РАН, Москва, Россия \\ ${ }^{2}$ Институт вулканологии и сейсмологии ДВО РАН, Петропавловск-Камчатский, Россия
}

\begin{abstract}
Аннотация: Представляется методика создания и содержание новой базы данных об активных разломах Евразии (БД), интегрировавшей в едином формате материал, накопленный к настоящему времени многими исследователями, включая авторов БД. Она вмещает более 20 тыс. географически привязанных объектов разломов, зон разломов и связанных с ними структурных форм с признаками последних перемещений в позднем плейстоцене и голоцене. Масштаб, в котором составлена БД, - 1:500000, а базовый демонстрационный масштаб - 1:1000000. Каждый объект БД снабжен двумя видами характеристик (атрибутов) - обосновывающими и оценочными. Обосновывающие атрибуты содержат сведения об объектах - их названия, данные о морфологии и кинематике, амплитуды смещений за разные отрезки времени, рассчитанные по ним скорости движений, возраст последних зафиксированных признаков активности, проявления сейсмичности и палеосейсмичности, соотношения объектов с параметрами коровых землетрясений и другие характеристики, а также сведения об источниках информации, список которых приложен к БД. Оценочные атрибуты - это система индексов, отражающих кинематику разломов согласно принятой в структурной геологии типизации, ранг скорости позднечетвертичных движений (три градации) и степень достоверности выделения структуры как активной (четыре градации). Индексы позволяют сопоставлять объекты по любому из атрибутов компьютерным способом между собой и с любыми другими видами оцифрованной информации с помощью любой ГИС-программы. Таким образом, БД дает возможность для получения сведений о разломах и решения более общих задач - тематического картографирования, определения параметров современных геодинамических процессов, оценки сейсмической и других геодинамических опасностей, тенденций тектонического развития на последнем, плиоцен-четвертичном, этапе развития Земли. Формат построения БД допускает ее постоянное пополнение и коррекцию с появлением новых сведений.
\end{abstract}

Ключевые слова: активные разломы; методика составления и содержание базы данных

\section{1. ВВЕДЕНИЕ}

Базы данных (БД) представляют собой важный инструмент современных научных исследований. Однозначность и однородность представления информации в форме базы данных открывают широкие и разнообразные перспективы изучения геологических феноменов (автоматизированной обработки и комплексного анализа их характеристик).

Основным содержанием предлагаемой базы данных являются активные разломы - тектонические нарушения, перемещения по которым происходили в недавнем прошлом. Следы движений за ближайший к современности интервал времени, отвечающий максимальному известному периоду повторяемости сильных коровых землетрясений, т.е. примерно за последние 30 тыс. лет [Kozhurin et al., 2008; Trifonov, Kozhurin, 2010], являются основанием предполагать, что подвижки возможны и в ближайшем будущем. Поскольку во многих областях подвижки этого времени трудно отделить геологическими и геоморфологическими методами от подвижек в более ранние стадии позднего плейсто- цена, мы считаем активным разлом, по которому зарегистрированы проявления движений в течение позднего плейстоцена и голоцена, т.е. за последние 130 тыс. лет [Trifonov, Machette, 1993]. Выраженность подвижек в смещениях молодых форм рельефа и отложений, а иногда и техногенных сооружений является главным поисковым, картировочным и оценочным признаком активного разлома. Методика таких исследований изложена в многочисленных публикациях [Wallace, 1968; Sieh, 1978; Trifonov, 1983, 1985; National Research Council, 1986; McCalpin, 1996; Yeats et al., 1997; Kozhurin, 2004, 2013; Trifonov, Kozhurin, 2010; и дp.]. Польза БД двойная: практическая (оценка разного рода геодинамических опасностей, прежде всего сейсмической) и теоретическая (расширение возможностей изучения новейшего и активного тектогенеза). Последнее определяется тем, что объекты БД (активные разломы) являются по определению геологически одновозрастными структурами, отражающими синхронные тектонические движения. Это позволяет сравнивать современную геодинамику и структуру удаленных и разнообразных регионов. 
В 1996 г. многолетняя работа, в которой в рамках Международного проекта II-2 «Карта крупных активных разломов мира» Международной программы «Литосфера» участвовало более 70 исследователей из 50 стран, привела к созданию электронной БД об активных разломах Евразии, включившей информацию о более чем 10000 разломов значительной части Евразийского континента и прилегающих акваторий. Работу по проекту для территории Евразии возглавлял В.Г. Трифонов, а в обобщение представленных исследователями материалов в виде базы данных решающий вклад внесли А.И. Кожурин, Д.М. Бачманов, Г.А. Востриков, А.И. Иоффе и Р.В. Трифонов. Эта база данных (БД-96) стала выдающимся достижением геоинформатики как в отношении методики формализации геологических данных, так и по общему объему содержавшейся в ней информации. Впервые на такую обширную территорию по единой методике был собран настолько объемный и детальный материал, удобный для сопоставления с другими материалами и пригодный для всестороннего анализа с применением различных алгоритмов компьютерной обработки.

Для БД-96 был разработан формат записи данных, сочетающий возможность фиксации большого числа параметров, компактность представления информации и четкость алгоритма формализации исходных сведений. Данные о каждом объекте составляли отдельный блок текста, включающий серию строк со значениями его параметров и серии строк с координатами узлов линии разлома. Каждая строка параметров начиналась числовым маркером, обозначавшим то свойство объекта, значение которого приводилось в этой строке. Запись в таком формате была пригодна для программной обработки по каждому отдельному параметру. На основе БД-96 были построены Карта активных разломов Евразии масштаба 1:5000000 [Trifonov, 1997, 2004] и карты и каталог активных разломов центральных сегментов Альпийско-Гималайского пояса [Trifonov et al., 2002]. БД-96 и созданные с ее помощью сейсмотектонические материалы были использованы при создании Комплекта карт общего сейсмического районирования территории Российской Федерации ОСР-97 [Ulomov, Shumilina, 1999].

Вместе с тем у БД-96 были недостатки, обусловленные как техническими возможностями того времени, так и неравномерной изученностью активных разломов. Так, детальность отображения, точность географической привязки и общий стиль представления данных существенно различались в разных регионах, что затрудняло их сопоставление. Из-за формального наложения друг на друга материалов разных авторов местами появлялись нереалистичные соотношения и сочленения объектов, например их взаимные пересечения. Сложная система записи атрибутики разломов требовала от пользователей знания большого числа условных маркеров и создавала проблемы при группировке объектов по нужным свойствам и программной обработке данных. Большая доля разломов не была обеспечена достоверными данными для обоснования значений ключевых параметров, а различная полнота характеристики разных регионов нередко создавала ложное впечатление о их разной тектонической активности. Возраст последних движений зачастую не был убедительно обоснован и назначался по результатам дешифрирования космических изображений невысокого разрешения. В результате в БД-96 оказались включены разломы с плиоцен-раннечетвертичными последними подвижками, и эти структуры не были четко отделены от действительно активных. Значение параметров присваивалось протяженным объектам, хотя точные и достоверные данные имелись лишь для их коротких участков. В некоторых регионах одни и те же параметры безосновательно присваивались сериям разломов, в других чрезмерная детальность и многословность характеристик затрудняли сравнение объектов.

После создания БД-96 появилось много новых данных об активных разломах, в том числе в виде разнообразных картографических материалов. Среди них есть региональные и обобщающие работы, изданные в виде бумажных карт или электронных баз данных. Таковы карты Италии [Galadini et al., 2001], Турции [Emre et al., 2013], Сирии [Trifonov, Ammar, 2012], Ирана [Hеssami et al., 2003], Филиппин [Distribution of Active Faults..., 2008], Таиланда [Kosuwan et al., 2006], а также базы данных для Южной Европы [Basili et al., 2013], Иберийского полуострова [García-Mayordomo et al., 2012], Франции [Jomard et al., 2017], Афганистана [Ruleman et al., 2007], Восточной Сибири [Lunina, 2016], Тибетско-Гималайского региона [Taylor, Yin, 2009] и др. Каждый из этих материалов содержит ценную информацию, однако они составлены по разным методикам и в разных форматах, имеют разную точность отображения объектов, разные число и смысл фиксируемых параметров, различаются пониманием термина «активный разлом» и в результате трудно сопоставимы. Карты и базы данных часто ограничены государственными границами или диктуемыми производственными нуждами рамками, которые секут геотектонические элементы. Это не позволяет воспринимать и оценивать их как целостные структуры в контексте более широкой геодинамической обстановки. Многие новые материалы имеют те же недостатки, что и БД-96: погрешности топографической привязки объектов; неоднородную детальность их изображения, мешающую целост- 
ному восприятию системы активных структур; неполную характеристику разломов без обоснования ключевых параметров или ссылок на источники данных, где они приводятся; присвоение сериям объектов одних и тех же параметров; неоправданную экстраполяцию параметров на всю длину протяженного объекта. Все это затрудняет сопоставление данных, создает сложности для их программной обработки.

Накопление новых сведений и представлений об активной тектонике Евразии требовало комплексного представления всего объема добытых знаний, как содержавшихся в БД-96, так и полученных позднее, т.е. создания новой базы данных об активных тектонических нарушениях (далее БД), где все имеющиеся сведения были бы переосмыслены с общих позиций и представлены в единой системе записи. Эта система должна быть удобной для пользователя и допускать возможность быстрого сопоставления данных по ключевым параметрам и их совмещение с другими видами оцифрованной информации. БД должна представлять собой непрерывно дополняемую и уточняемую геоинформационную систему, интегрирующую по единой методике все материалы, имеющие отношение к активной тектонике, независимо от того, каковы были методы, детальность и достоверность материалов и теоретические представления авторов.

Принципами составления БД должны быть геодинамическая целостность предмета изучения, методическая однородность обработки включаемых сведений, непрерывность процесса дополнения и уточнения материала, комплексность получаемого материала на основе учета результатов всех исследований активной тектоники. БД должна стать средством накопления и регулярного уточнения данных об активных разломах, достоверность которых повышалась бы в результате последовательной интеграции в БД новых сведений; объединить в рамках единой методики отбора и представления данных разнородные и территориально разрозненные сведения по активной тектонике; создать геоинформационный материал, отражающий активную тектонику Евразийской плиты и ее обрамлений как целостной системы.

БД, отвечающая вышеуказанным требованиям, создана на основе БД-96 с помощью пакета программ ArcGIS. Формат записи и система параметров БД существенно модифицированы. Разработаны методы ее пополнения новыми материалами, их редактирования и интерпретации для обеспечения единства системы параметров и формата записи объектов. Выявлены дополнительные аспекты активной тектоники, позволившие более полно представить накопленный материал и определить места дальнейших исследований (рис. 1).

\section{2. ПРИНЦИПЫ И МЕТОДЫ СОЗДАНИЯ БАЗЫ ДАННЫХ}

\section{1. РЕДАКТИРОВАНИЕ ОБЪЕКТОВ БАЗЫ ДАННЫХ}

Общие положения. Объектами БД являются активные разломы и зоны разломов, а также активные флексуры и складки, под которыми предполагается наличие разлома, и зоны глубинных нарушений, выраженные в геофизических полях и проявленные на поверхности лишь косвенными признаками. Структурным выражением объекта БД является сам разлом и весь комплекс сопутствующих ему активных элементов, среди которых может преобладать разрывная или складчатая составляющая. Линия разлома обычно соответствует наиболее выраженному и выходящему на поверхность разрывному элементу зоны. В качестве объектов БД могут выделяться отдельные сегменты разломов и разломных зон, если они обособлены от соседних сегментов и/или отличаются от них. Отличия могут быть выражены изменением морфологии, кинематики или простирания разлома; изменением его выраженности в рельефе, например появлением или исчезновением связанных с разломом уступов, ложбин и гряд; разделением единого разлома на отдельные ветви или примыканием других разломов; изменением характера сейсмичности. Только на такой сегмент распространяются сведения об активных движениях, полученные при исследованиях в его пределах, и только с ним соотносятся ближайшие к нему эпицентры землетрясений.

Контекстные материалы. При редактировании и оценке объектов БД используются контекстные материалы - комплект данных, непрерывно и однообразно покрывающих всю территорию Евразии и надежно привязанных к местности. На основе сопоставления с контекстными материалами осуществляется обязательный контроль характеристик каждого объекта БД, что позволяет рассматривать их совокупность в качестве единой системы. Важнейшим из таких материалов является топооснова, в качестве которой выбрана цифровая модель рельефа 3-сек разрешения SRTM V3 (базовая топооснова). Путем сопоставления с ней все объекты приводятся к единому уровню детальности изображения и точности расположения. Второй элемент комплекта - мозаика цветных космоснимков LandSat ETM+ 15-метрового разрешения. На основе их дешифрирования осуществляется контроль расположения объектов в областях со слаборасчлененным рельефом, детализация внутреннего строения разломных зон, иногда выявляются признаки активности структур и дается предварительная оценка их кинематики. В комплект входят также сейсмологические данные, заимствованные 
из различных каталогов. Сопоставление с ними, учитывающее наклон разлома, используется для уточнения положения и параметров объектов БД в качестве косвенных признаков.

Стандартные масштабы рассмотрения. Интерпретация результатов составления БД зависит от масштаба, в котором дешифрируются контекстные материалы, редактируются объекты и оцениваются их параметры. Рабочий масштаб, в котором производится редактирование и оценка объектов непосредственно в процессе составления БД, ограничен разрешением базовой топоосновы. Вместе с тем он должен быть достаточно генерализованным, чтобы обеспечить качественное изображение модели рельефа при его дешифрировании. В качестве рабочего масштаба редактирования выбран масштаб 1:500000. Масштаб, в котором предполагается визуализация БД в виде карты и интерпретация ее пользователем (базовый масштаб представления), должен обеспечивать качественное изображение объектов, отредактированных в рабочем масштабе. Он учитывает детальность изображения, характерную для региональных карт активных разломов как основных материаловисточников для БД, и должен быть достаточно крупным, чтобы обеспечивать возможность уточнения внесенных с них данных, поэтому в качестве базового демонстрационного выбран масштаб 1:1000000.

Редактирование конфигурации объектов. Перенос линий объектов из различающихся по детальности материалов-источников в БД не является формальным. Если важные структурные элементы на материалах-источниках изображены недостаточно детально или смещены относительно реального местоположения, их позиция и конфигурация уточняются по результатам дешифрирования базовой топоосновы или космоснимков, с возможным разделением на несколько объектов, если при дешифрировании элемент обнаруживает сложное строение или разную выраженность в разных своих частях. Если структурные элементы в материалах слишком детализированы, они генерализуются с возможным объединением смежных элементов в единый объект. Все объекты БД приводятся к виду, когда интервалы между узловыми точками их линий сопоставимы. Число описывающих объект точек должно быть не менее четырех, а максимальный угол изгиба в узловой точке не должен превышать 45․ Таким образом, все вносимые в БД объекты приводятся к единой детальности изображения и стандартным геометрическим характеристикам.

При дешифрировании линий объектов БД предполагается, что активный разлом так или иначе выражен в рельефе. Независимо от того, как струк- тура объекта выражена на более детальных материалах, в БД линии объектов проводятся по тем дешифровочным элементам рельефа (уступам, ложбинам, грядам), которые различимы на базовой топооснове, с учетом кинематики, указанной в источнике или предполагаемой из контекста. Случаи, когда линия разлома остается не согласованной с рельефом в рабочем масштабе, допускаются, если она в таком виде была закартирована непосредственно на местности или детальном снимке. Условием включения новых объектов в БД является согласованность их кинематики с уже имеющимися в БД смежными объектами, структурная целостность и непротиворечивость системы нарушений. В природе не встречаются простые (без локальных усложнений) пересечения активных структур. Так, пересечение сдвиговых зон приводит к их искривлениям и последовательному развитию новых отрезков обеих зон [Trifonov et al., 1993], поэтому пересечение объектов без наличия указанных признаков, как и близкое расположение параллельных разнонаправленных сдвигов, не допускается в БД. Обычно крестообразные наложения возникают при наложении объектов, заимствованных из разных источников. В этих случаях одному из них присваивается меньшая достоверность, и этот объект в точке пересечения разделяется и корректируется для получения реалистичного кинематического соотношения.

Соотношение частных данных и обобщений. Сведения об общей региональной структуре учитываются посредством включения в БД результатов обобщающих исследований, обзорных карт и других баз данных, отражающих результаты уже проведенной интерпретации первичной полевой информации. Параметры, следующие из таких обобщений, включаются в БД либо на участках, где свойства уже существующих объектов им не противоречат, либо если на основе дешифрирования можно создать новый объект, соответствующий обобщению, или несколько объектов, различающихся по степени соответствия свойствам, указанным в материале-источнике для зоны в целом.

Разные авторы по-разному интерпретируют структуру, и при наложении в БД независимые материалы могут отчасти противоречить друг другу. Тем не менее вся совокупность сведений по возможности фиксируется и интегрируется в общую систему объектов БД. Это обеспечивает возможность разных вариантов ее интерпретации, что важно для построения различных гипотез и планирования дальнейших исследований. Цель составления БД - максимально полно и всесторонне представить все многообразие элементов системы активных нарушений. Признаки же ключевых составляющих этой системы будут естественным 


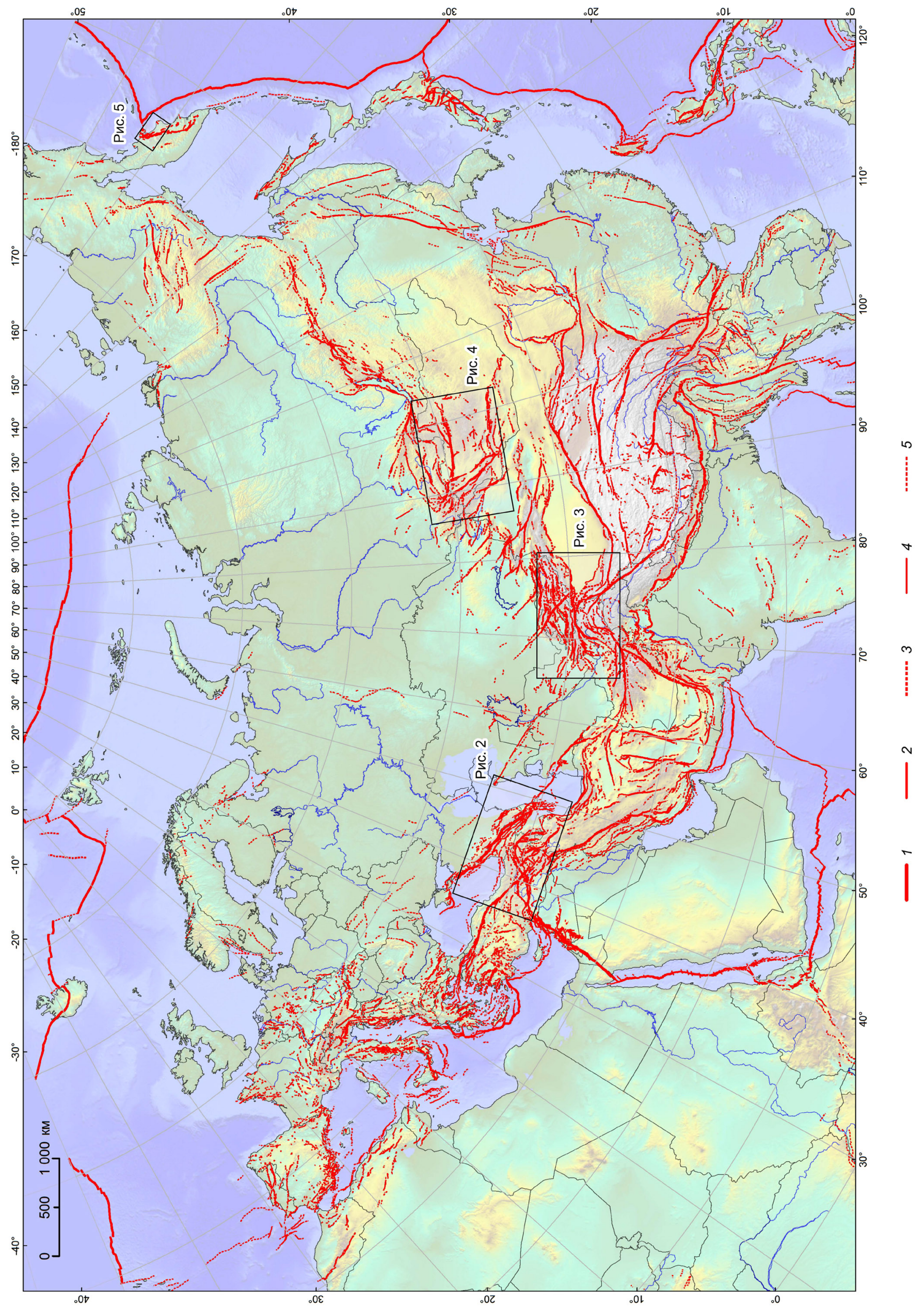


Рис. 1. Визуализация Базы данных об активных разломах Евразии: упрощенная (без разломов с достоверностью D) карта разломов.

1-5 - активные разломы со скоростями движений разного ранга и разной достоверностью активности: 1 - ранг 1 и достоверность А и В, 2 - ранг 2 и достоверность А и В, 3 - ранг 2 и достоверность С, 4 - ранг 3 и достоверность А и В, 5 - ранг 3 и достоверность С. Черными рамками показаны контуры рис. 2-5.

Fig. 1. Visualization of the Active Faults of Eurasia Database: a simplified fault map (faults with reliability degree D are not shown).

1-5 - active faults characterized by the displacement rates of various ranks $(1,2,3)$ and different degrees of reliability of activity determination (A, B, C): 1 - rank 1 and reliability A and B, 2 - rank 2 and reliability A and B, 3 - rank 2 and reliability C, 4 - rank 3 and reliability A and $B, 5-$ rank 3 and reliability C. The black boxes show the contours of Fig. 2-5.

образом проявляться в совокупном материале БД по мере включения в нее все новых локальных данных о конкретных объектах.

Складывающаяся система объектов БД является результатом анализа их частных соотношений в локальном масштабе. При этом производится локальная взаимная увязка свойств редактируемого и смежных объектов на основе структурных и кинематических принципов. Запрещается оценивать соотношения объектов, исходя из общих представлений об окружающей структуре и возможной позиции объектов в широком геодинамическом контексте. Региональная ситуация не должна быть основанием для оценки данных. Напротив, она является результатом составления БД и проявляется при целостном восприятии материала в более общем масштабе как форма представления новых знаний.

При рассмотрении пользователем всей системы объектов БД в генерализованном региональном масштабе она становится основой для проведения дальнейшего анализа. При этом должна приниматься во внимание значимость отдельных объектов, определяемая по достоверности их активности и скоростям движений. Ценность представляют и конкретные данные по отдельному объекту, и та позиция в общей структуре, которую он занимает. БД создается для того, чтобы использовать характеристики объектов для решения научных и практических задач, а также чтобы предоставить исследователю целостную картину распределения активных деформаций.

\section{2. ИСХОДНЫЕ МАТЕРИАЛЫ ДЛЯ БД}

Общий подход. При составлении БД важна однородность сведений о проявлениях активной тектоники всей области покрытия БД без априорного разделения ее на высокоактивные и стабильные территории, хотя в последних активные структуры редки и малодостоверны. Исходные описания активных структур, карты и базы данных разных ре- гионов различаются объемами отображаемой в них информации, при этом могут плохо соотноситься и даже противоречить друг другу, особенно если они созданы в разное время и разными методами. Это иногда создает ложное впечатление о различиях геодинамической обстановки и степени активности. В БД включаются все сведения, имеющие отношение к активной тектонике, учитываются все обоснованные представления и модели. При этом ставится задача нивелировать указанные расхождения на основе единообразных критериев оценки параметров активности.

Экспертные мнения как тип сведений. Специфика геологических исследований состоит в том, что приводимые в источниках свойства разломов (например, полевые замеры их характеристик) могут являться результатом субъективных оценок, которые нередко различаются у разных наблюдателей одного явления. В качестве доказанных фактов часто выступают экспертные мнения исследователей. Это вносит долю условности при разделении информации на объективные данные и субъективные мнения, основанные, в свою очередь, на собственных первичных данных или обобщении чужих интерпретаций. Корректно опубликованное независимое мнение компетентного исследователя является результатом дополнительной обработки и осмысления всего комплекса фактических данных, поэтому при составлении БД кроме сведений, заявленных в материалах-источниках как фактические данные, для обоснования свойств объектов используются экспертные заключения, часто представляемые в виде карт.

Удельный вес экспертных оценок и вторичных интерпретаций в совокупности обоснований заведомо ниже, чем у первичных данных, причем значимость таких мнений зависит от квалификации и научного авторитета экспертов, от степени согласованности их оценок. При прочих равных условиях большая значимость присваивается более свежим публикациям. При включении в БД экспертных мнений составители БД оценивают их обоснован- 
ность результатами дешифрирования контекстных материалов и то, как они вписываются в имеющуюся совокупность данных. Составители БД не переосмысливают экспертные заключения на основе обобщающих моделей. По мере накопления данных влияние субъективных факторов на оценку тех или иных активных разломов и зон нивелируется. БД является авторской в отношении оценки свойств отдельных объектов и, вместе с тем, способом интеграции и обобщения данных и мнений разных исследователей. Это позволяет выявлять общие свойства системы активных деформаций, несмотря на многообразие и разнородность ее частных элементов.

Учет данных по новейшей тектонике. Перемещения по активным разломам, как правило, являются продолжением ранне- и среднеплейстоценовых, плиоценовых, а в целом - новейших движений и наследуют их основные параметры. В связи с этим оправданным является привлечение при составлении БД материалов не только по собственно активной, но и по новейшей тектонике. При составлении БД принимаются во внимание только разломы, проявлявшие активность на второй стадии неотектонического этапа и горообразования, которая в одних регионах охватывает плиоцен квартер (иногда также конец миоцена), а в других только квартер и в течение которой не было кардинальных изменений структурного плана. Могло изменяться лишь внутреннее строение разломных зон при сохранении общего направления движений.

Задачей составителей БД является анализ неотектонических материалов и оценка их элементов на предмет соответствия критериям выделения активных структур. Эти материалы представлены, как правило, разнообразными картами, схемами и базами данных, содержание которых определяется лишь легендой и не предусматривает обоснование характеристик отдельных структур. Интерпретация их возраста является экспертным мнением автора материала, причем разломы, обозначенные у одних исследователей как новейшие, у других нередко отнесены к активным.

Среди новейших разломов выделяются три категории. Первая представлена активными разломами, унаследованно развивавшимися в течение квартера или плиоцен-квартера. Учет допозднеплейстоценовых смещений по ним позволяет уточнить структурно-кинематические параметры, скорости перемещений и, в конечном счете, значимость таких активных разломов. Ко второй категории относятся новейшие разломы, которые присутствуют на неотектонических картах и при дешифрировании детальных дистанционных материалов и анализе сейсмичности обнаруживают признаки движений в позднем плейстоцене - голоцене. Такие новейшие разломы включены в БД с той или иной достоверностью активности. Наконец, третью категорию образуют плиоцен-четвертичные или четвертичные разломы, по которым позднечетвертичные подвижки пока не выявлены, но анализ контекстных материалов допускает, что они могут быть обнаружены, хотя бы фрагментарно, при дальнейших исследованиях. Они включены в БД с минимальной достоверностью активности, поскольку их параметры уточняют общую структурно-динамическую ситуацию в регионе, а некоторые активные разломы связаны с ними структурно или динамически. Их включение в БД помогает планировать дальнейшее изучение новейших структур на предмет определения их активности.

Указанные обстоятельства делают необходимой более дробную дифференциацию активных структур по их достоверности. Для каждого объекта анализируется вся совокупность сведений и экспертных заключений и его позиция по отношению к смежным объектам. На основе такого анализа производится оценка достоверности активных структур. В высокоактивных областях, насыщенных активными разломами, требуется большая строгость обоснования при внесении в БД неотектонических элементов со слабовыраженными признаками активности. В слабоактивных областях, где достоверно активных разломов почти нет, с неотектонической карты может вноситься в БД с минимальной достоверностью больше элементов, обнаруживающих сходство с активными структурами в контекстных материалах. При сопоставлении нарушений с разным возрастом последних движений важна степень обобщения их структурных элементов. При детализации материала выраженность унаследованности активных нарушений от новейших снижается, поскольку со временем могут проявляться изменения внутреннего строения разломных зон. Начиная с некоторой степени генерализации, расположение элементов активной тектоники все более соответствует структурному плану нарушений, активных на прежних стадиях плиоцен-четвертичного развития. С учетом этого масштаб редактирования БД выбран достаточно генерализованным, чтобы рассматривать активные нарушения как унаследованные от новейшей структуры и использовать неотектонические карты для поиска проявлений активной тектоники.

Интеграция разнородных сведений. Разные исследователи, исходя из имеющихся у них данных и представлений, предлагают разные варианты карт, отражающих черты активной тектоники одной и той же территории. В БД интегрируются все материалы по мере их поступления, без предварительного выбора условно правильных. При этом 
выбор конкретных сведений для включения в БД ограничен отдельными структурными элементами, а вся система объектов совершенствуется путем накопления данных, отражающих различные сведения и мнения. Это осуществляется посредством указания авторства каждого фрагмента сведений об объекте и переоценки его атрибутов в зависимости от совпадения или противоречия мнений разных авторов.

Если новые данные не соответствуют уже имеющимся в БД сведениям, то внимание обращается на степень их обоснованности. При сопоставимом уровне фактического обоснования относительно большая достоверность присваивается более современным представлениям. При сравнении исследований с близкими датами публикаций более высокую обоснованность определяют топографическая детальность исследования, насыщенность конкретными сведениями, совершенство методов и технологий, научная репутация авторов, четкость формулировки результата и его картографического представления. По мере поступления новых данных изменяется оценка достоверности объекта и определения его параметров. Возможно удаление объекта, если он был слабо обоснован, а новые уверенные данные противоречат его существованию. Основной принцип состоит в том, чтобы изменять прежнее с учетом нового, не отвергать прежнее, а дополнять. Этот подход отражает историю изучения территории и обеспечивает его преемственность. Если с поступлением новых данных наступает перенасыщение, мешающее восприятию в базовом масштабе, то производится фрагментарное прореживание системы объектов. Удаляются малодостоверные фрагменты.

Таким образом, развитие БД представляет собой последовательный процесс уточнения представлений об активной тектонике, обеспечивающий преемственность и интеграцию результатов работы разных исследователей. Применение этой методики ведет к повышению информационной ценности и аналитического потенциала БД как исходного материала для тематических исследований и призвано показать разнообразие современного тектогенеза и способствовать постановке задач дальнейших работ.

Свою задачу составители БД видели в том, чтобы, рассматривая в рабочем масштабе каждый фрагмент материала, дополнять новыми сведениями и экспертными заключениями ранее включенные в БД-96 данные и оценки; уточнять и исправлять расположение и детальную форму объектов; оценивать значения атрибутов новых разломов с учетом свойств уже сложившейся на рассматриваемом участке системы объектов и, если это оправдано, изменять значения атрибутов старых объек- тов по новым данным. В качестве примеров такого интегрирования представлены карты активных разломов Кавказского, Памиро-Тянь-Шаньского, Алтае-Саяно-Хинганского и Центрально-Камчатского регионов (рис. 2-5).

\section{3. ОПИСАНИЕ СВОЙСТВ ОБЪЕКТОВ БАЗЫ ДАННЫХ}

\section{1. ОБОСНОВЫВАЮЩИЕ И ОЦЕНОЧНЫЕ АТРИБУТЫ ОБЪЕКТОВ}

Геометрия объектов БД определяется координатами узлов их линий в шейп-слое, созданном в результате векторизации бумажных карт или конвертации из баз данных источников (с последующей коррекцией их положения по контекстным материалам). Более сложная задача заключается в поиске способа формализации характеристик объектов, который сохранял бы все важные сведения из материалов-источников и при этом предоставлял широкие возможности для сравнения и ранжирования объектов.

БД использует формат записи, при котором геологические характеристики и их обоснования для всех объектов собраны в общей таблице, где каждому объекту соответствует отдельная строка, в которой и производится запись всех сведений о нем. В этой строке каждой характеристике объекта отвечает свой фрагмент строки, называемый полем. Содержанием поля является значение соответствующего атрибута объекта БД.

Ниже приведены атрибуты объекта БД в порядке их заполнения.

AUTH - ссылки на материалы-источники данных об активности структуры.

NAME - наименование активной структуры и (или) включающей ее структурной зоны.

PARM - характеристики активной структуры, записанные в определенном формате.

TЕХT - дополнительные сведения об активной структуре, в свободной текстовой форме.

SNS1 - главная компонента движения, преобладающий кинематический тип.

SNS2 - второстепенная компонента, меньшая по амплитуде или менее выраженная.

SIDE - идентификатор относительно поднятого крыла структуры.

RATE - ранг скорости молодых тектонических движений в пределах структуры.

CONF - ранг достоверности оценки нарушения как активной структуры.

Комплекс атрибутов, выбранных для ранжирования объектов БД, представляется достаточным, чтобы отразить все главные и часто востребованные характеристики активных структур. Вместе с тем он включает лишь те параметры, которые с 


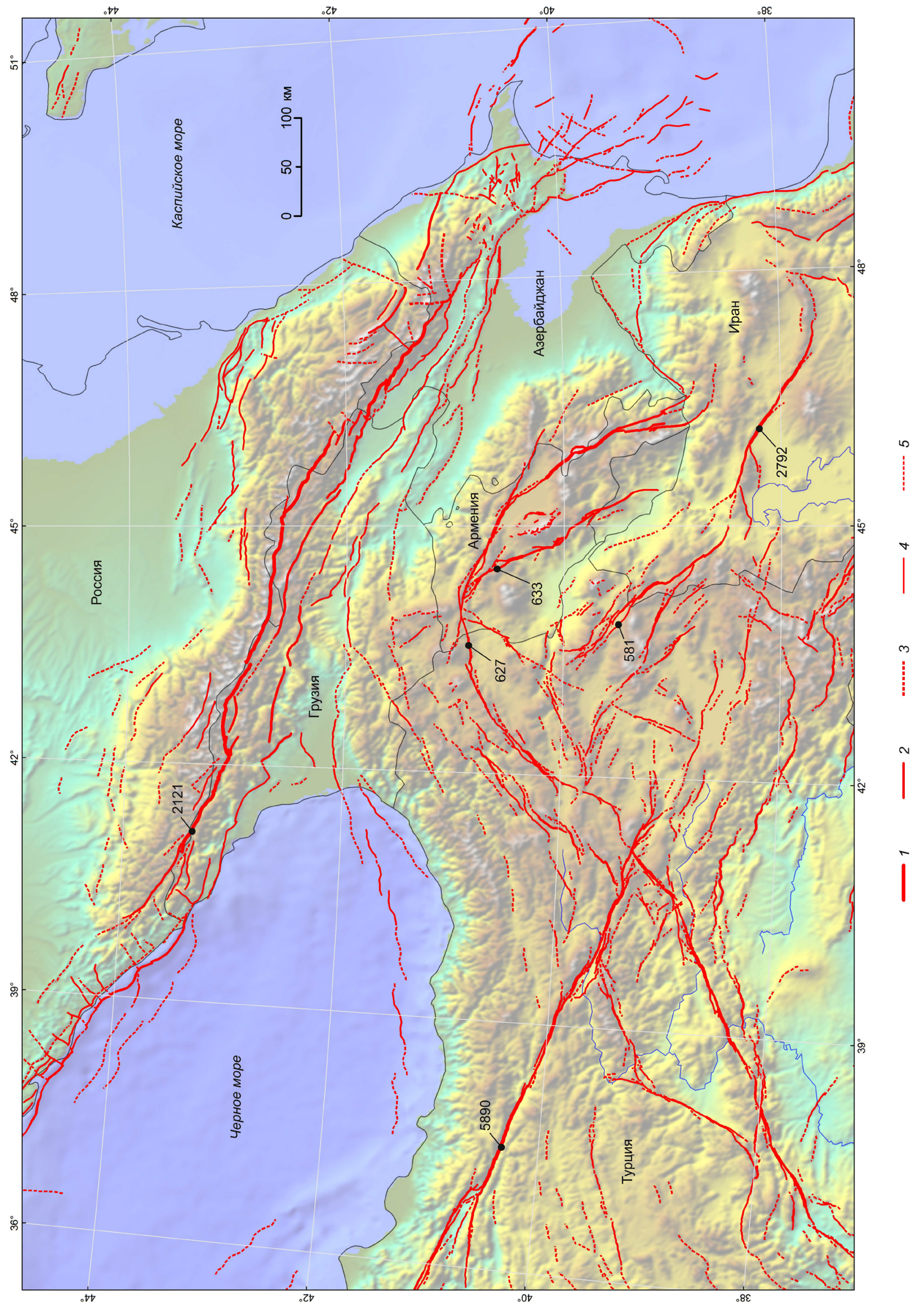


Рис. 2. Визуализация Базы данных об активных разломах Евразии: упрощенная (без разломов с достоверностью D) карта разломов Кавказского региона. Условные обозначения см. на рис. 1. Точки с вынесенными цифрами - разломы, представленные в таблице.

Fig. 2. Visualization of the Active Faults of Eurasia Database: a simplified fault map of the Caucasus region (faults with reliability degree D are not shown). See the legend in Fig. 1 . The faults listed in the table are marked by circles with numbers.

наибольшей вероятностью можно оценить на практике. Важные сведения, которые имеются лишь для малой доли разломов, обязательно фиксируются, но только как дополнительная часть атрибутов, предназначенных для всестороннего описания объектов.

При составлении БД для каждого объекта заполняются ключевые поля таблицы атрибутов, поскольку сама возможность внесения объекта в БД обусловлена наличием определенных данных. Так, для каждого объекта БД приводятся источники сведений о нем, преобладающая кинематика, ранг скорости и оценка достоверности активности. Для сопоставления данных по различным наборам атрибутов важно заполнить максимальное число полей таблицы значимой информацией в определенном формате.

Атрибуты объектов БД разделены на два типа: максимально объективные первичные данные (обосновывающие атрибуты) и предложенные составителями БД вторичные индексы (оценочные атрибуты). Содержание обосновывающих атрибутов, где приводятся конкретные сведения из материалов-источников со ссылками на них, предназначено для обоснования оценочных атрибутов. Их значения являются производными от содержания обосновывающих атрибутов и позволяют дифференцировать и сравнивать объекты, но оказываются иногда условными и даже предполагаемыми на основе соотношений со смежными объектами и общего фона значений рассматриваемого параметра в регионе.

\section{2. ХАРАКТЕРИСТИКА ОБОСНОВЫВАЮЩИХ АТРИБУТОВ}

Обосновывающие атрибуты AUTH, NAME, PARM и TEXT максимально точно и полно представляют те сведения, которые присутствуют в материалахисточниках. Эти сведения отражены в атрибутах как непосредственно - в виде кратких конкретных характеристик объектов, так и косвенно - в виде ссылок на источники, содержащие развернутое описание и обоснование этих характеристик.

Обосновывающие атрибуты составляют главную ценность при использовании БД в качестве исходного материала для разнообразных темати- ческих исследований. Эти атрибуты позволяют пользователю БД узнать наиболее значимые установленные свойства объекта и его экспертные оценки от разных авторов, а также составить представление о качестве источников сведений, которые стали основанием для включения объекта в БД. Обосновывающие атрибуты предоставляют исследователю возможность проверить корректность приведенных в БД оценок свойств объектов и произвести их переоценку.

Обосновывающие атрибуты форматированы. Для выражения точного смысла вносимых сведений они допускают разнообразие своего содержания, но лишь в рамках четких правил его оформления. Содержание атрибута представляет строка длиной до 256 символов, позволяющая привести все важные сведения об объекте и состоящая из отдельных блоков, разделенных между собой условными знаками с обязательным указанием ссылок на авторство каждого источника. Недостатком обосновывающих атрибутов является то, что элементы содержания таких строк трудносравнимы, а программная идентификации их смысла сложна и не всегда однозначна.

Источники сведений. Содержанием атрибута AUTH являются ссылки на все источники сведений об объекте с указанием авторства и времени публикации или иной формы их предоставления. Качество материалов-источников, их разнообразие, независимость, репутация авторов и изданий, время публикаций являются важными критериями оценки содержания остальных атрибутов. Атрибут AUTH относится к обязательным, поскольку содержит информацию, без которой никакой объект не может быть включен в БД, и является ключевым, так как БД представляет собой, в том числе, форму организации и презентации всей совокупности мнений разных исследователей об активных разломах того или иного региона. Ссылки в атрибуте AUTH могут указывать не на первоначальный источник данных, а на обобщающие материалы с описанием групп разломов, каждый из которых был изучен в разное время разными авторами. По цепочке ссылок пользователь БД может найти материалы, в которых приводятся первичные данные с их интерпретацией. У многих объектов атрибут 


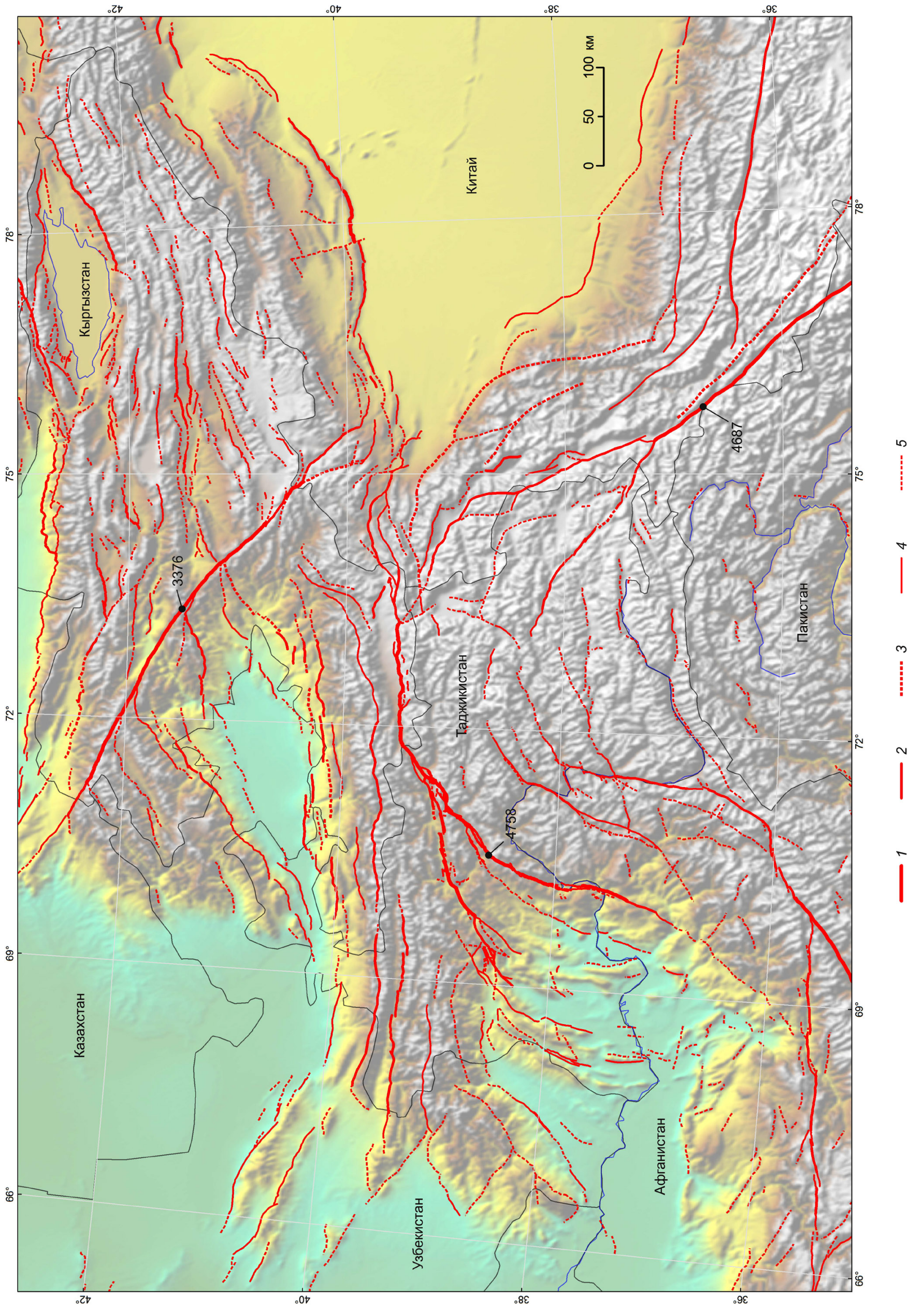


Рис. 3. Визуализация Базы данных активных разломов Евразии: упрощенная (без разломов с достоверностью D) карта разломов Памиро-Тянь-Шаньского региона. Условные обозначения см. на рис. 1. Точки с вынесенными цифрами - разломы, представленные в таблице.

Fig. 3. Visualization of the Active Faults of Eurasia Database: a simplified fault map of the Pamir - Tien Shan region (faults with reliability degree D are not shown). See the legend in Fig. 1 . The faults listed in the table are marked by circles with numbers.

AUTH является единственным обосновывающим атрибутом, что свидетельствует о их недостаточной изученности.

При форматировании атрибута AUTH фрагменты его содержания, относящиеся к разным источникам, разделяются точкой с запятой. Ссылки на источники оформлены в соответствии с правилами цитирования научных публикаций. Полные ссылки представлены в виде отдельного текстового приложения к БД. Если в качестве исключения атрибут отсылает к неопубликованным сведениям, то указывается источник и после ключевого слова «data» - год их получения.

Наименование структуры. В атрибут NAME вносятся указанные в материалах-источниках названия разломов и/или включающих их зон. Атрибут NAME является обосновывающим, поскольку, как правило, наличие и общепризнанность наименования объекта косвенно свидетельствуют о достоверности его выделения и полноте изученности. Если поименованная структура разделена на несколько объектов, всем им присваивается одно и то же название. Поле атрибута NAME ограничено 50 символами, поэтому при наличии у разлома нескольких названий менее употребительные или устаревшие переносятся в содержание атрибута TEXT. Наименование объекта вносится заглавными латинскими буквами в написании, приведенном в материале-источнике, или с использованием транслитерации. Допускается сокращение сложносоставных названий с сохранением их идентифицирующей части. После названия разлома добавляется обозначение «f.», а после наименования зоны разломов - «f.z.».

Основные характеристики. Содержание атрибута PARM представляет в БД главный источник фактической информации о возрасте последних движений, скорости перемещений, кинематических параметрах, сейсмической активности и других конкретных сведениях, взятых из материалов-источников. Этот широкий спектр сведений оформлен по определенным правилам записи в компактном виде, преимущественно в числовых значениях и символах-индексах. Атрибут PARM содержит сведения для определения значений оце- ночных атрибутов, в том числе достоверности активности.

Формат записи включает в себя элементы, названные маркерами свойств. После каждого маркера ставится знак равенства, за которым приводится значение свойства, обозначенного маркером. В качестве маркеров используются либо числовые индексы или различные сокращенные термины и обозначения свойств объекта, расшифрованные в прилагаемом к БД гиде для пользователя, либо названия параметров, взятые из цитируемых материалов-источников. Гибкость в обозначениях свойств позволяет точно и наглядно передать их смысл, но предпочтение отдается унифицированным, кратким и понятным любому пользователю маркерам.

После каждого блока данных, взятых из отдельного источника, приводится ссылка на этот источник в том же виде, как она указана в составе атрибута AUTH. Блоки сведений, перенесенные из БД96, расположены в начале строк и к ним в атрибуте AUTH относится весь комплекс ссылок до 1996 года. Эти блоки и блоки данных из разных других источников разделены знаком двойной косой черты (слэш). Внутри каждого блока сведения о разных свойствах объекта разделены точкой с запятой. Применение двойного слэша и точки с запятой при записи атрибутов делает возможной их программную обработку.

Дополнительные сведения. Атрибут ТЕХТ является факультативным, поскольку лишь дополняет характеристику объекта в атрибуте PARM и заполняется только при его переполнении, а также если какое-то значимое описание объекта не поддается формализации. Этот атрибут предоставляет сведения и доводы в формулировках, максимально близких к первоисточникам, и передает смысл, заложенный в них авторами. Атрибут содержит сведения в текстовой форме без применения маркеров свойств. При наличии места допускаются развернутые формулировки и описания объекта. Как и в атрибуте PARM, блоки сведений из различных источников разделены двойным слэшем, а описания разных свойств внутри блоков - точкой с запятой. После каждого блока приводится ссылка на 


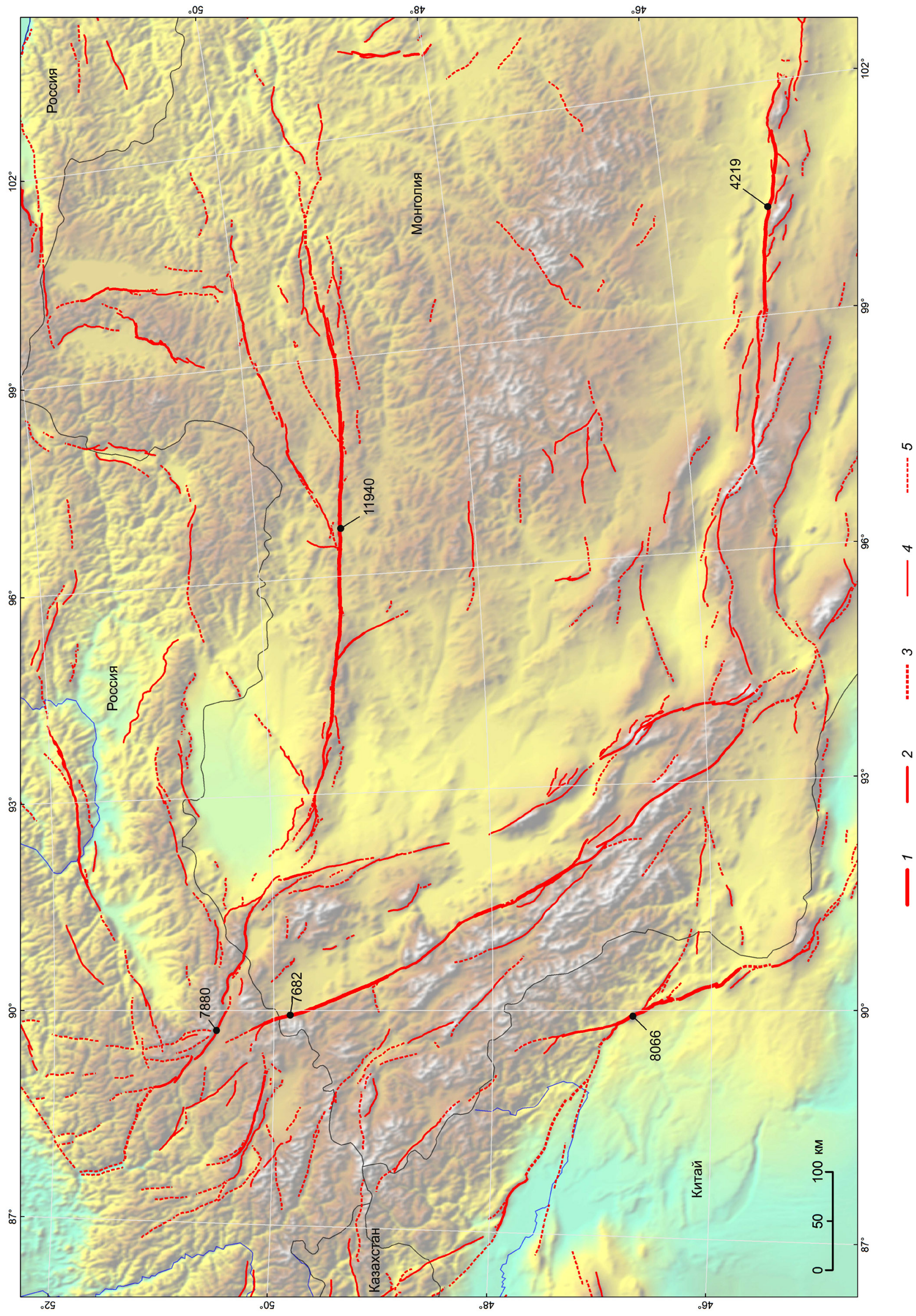


Рис. 4. Визуализация Базы данных об активных разломах Евразии: упрощенная (без разломов с достоверностью D) карта разломов Алтае-Саяно-Хинганского региона. Условные обозначения см. на рис. 1. Точки с вынесенными цифрами - разломы, представленные в таблице.

Fig. 4. Visualization of the Active Faults of Eurasia Database: a simplified fault map of the Altai-Sayan-Khingan region (faults with reliability degree D are not shown). See the legend in Fig. 1 . The faults listed in the table are marked by circles with numbers.

источник. Если важные новые сведения не помещаются в строку атрибута длиной 255 символов, старая запись сокращается.

Непосредственно в атрибутах PARM или TEXT содержится лишь компактный набор наиболее важных и достоверных сведений о характеристиках объекта как активной структуры. Менее значимые или менее достоверные сведения присутствуют в БД лишь в форме дополнительных ссылок на их источники в составе атрибута AUTH, где они могут быть найдены для детального изучения объекта. Наличие противоречий между сведениями из разных источников упоминается обязательно.

\section{3. ХАРАКТЕРИСТИКА ОЦЕНОЧНЫХ АТРИБУТОВ}

Оценочные атрибуты RATE, SNS1, SNS2, SIDE и CONF индексированы, т.е. их возможные значения выбираются из ограниченного списка индексов условных обозначений. Достоинством таких атрибутов является их удобство для сравнения объектов, программной обработки и построения карт согласно легенде. Выбор оценочных атрибутов осуществляется на основе обосновывающих атрибутов согласно экспертному мнению составителей БД. Если в обосновании содержатся противоречивые сведения, то выбор более достоверных из них или формулировку компромисса осуществляют составители БД. Если выбор невозможен, то допускается самостоятельная оценка атрибутов составителями БД с привлечением контекстных материалов. Отсутствие сведений в обосновывающих полях снижает оценку достоверности объекта. Атрибуты оценочного типа являются конечным результатом работы составителей БД.

Параметры кинематики. Кинематическая характеристика объекта БД представлена комплексом из трех атрибутов. Атрибут SNS1 (главная компонента движения) является обязательным, поскольку каждый объект БД соответствует той или иной структуре, характеризующейся определенным типом движений. Атрибут SNS2 (второстепенная компонента) является факультативным и его поле остается незаполненным, если главная компонента оказывается единственной. Атрибут SIDE (индикатор относительно поднятого крыла) заполняется только в том случае, если какой-либо из первых двух атрибутов указывает на присутствие вертикальной составляющей движения. Все эти атрибуты являются оценочными, поскольку для выбора их значений анализируется весь комплекс обосновывающих атрибутов, касающихся кинематики объекта, и контекстных материалов, и учитываются структурные соотношения со смежными объектами БД. Экспертная оценка указанных атрибутов делается, в том числе, и при несоответствии сведений из разных источников или недостатке полевых данных о смещениях.

Значениями атрибута SNS1 и SNS2 являются индексы: D - правый сдвиг, S - левый сдвиг, T надвиг, R - взброс, N - сброс, E - раздвиг, а также V, когда установлено наличие вертикального смещения, но не определен его сбросовый или взбросовый тип, и U, если кинематика неизвестна. Значениями атрибута SIDE могут быть индексы: +N поднято северное крыло структуры; +NE - северовосточное; +E - восточное; +SE - юго-восточное; +S - южное; +SW - юго-западное; +W - западное; +NW - северо-западное. Отсутствие значения атрибута SIDE допустимо лишь для сдвигов и раздвигов.

Главный критерий оценки кинематики объекта БД - точные и достоверные сведения из материалов-источников. Второй по значимости является выраженность нарушения в детальных моделях рельефа и на космоснимках. При недостатке точных данных и слабой выраженности в рельефе оценка кинематических параметров производится, исходя из характерных особенностей системы активных структур, включающей объект. Его кинематика должна соответствовать структурно-кинематическим закономерностям распределения разломных деформаций разных типов. Во всяком случае, она не должна противоречить кинематической ситуации в пределах анализируемого участка, рассматриваемого в рабочем масштабе. Если указанные в источнике сведения о кинематике объекта противоречат сложившимся в БД кинематическим соотношениям, то эти сведения фиксируются в обосновывающих полях, но соответствующие атрибуты могут остаться без оценки или 


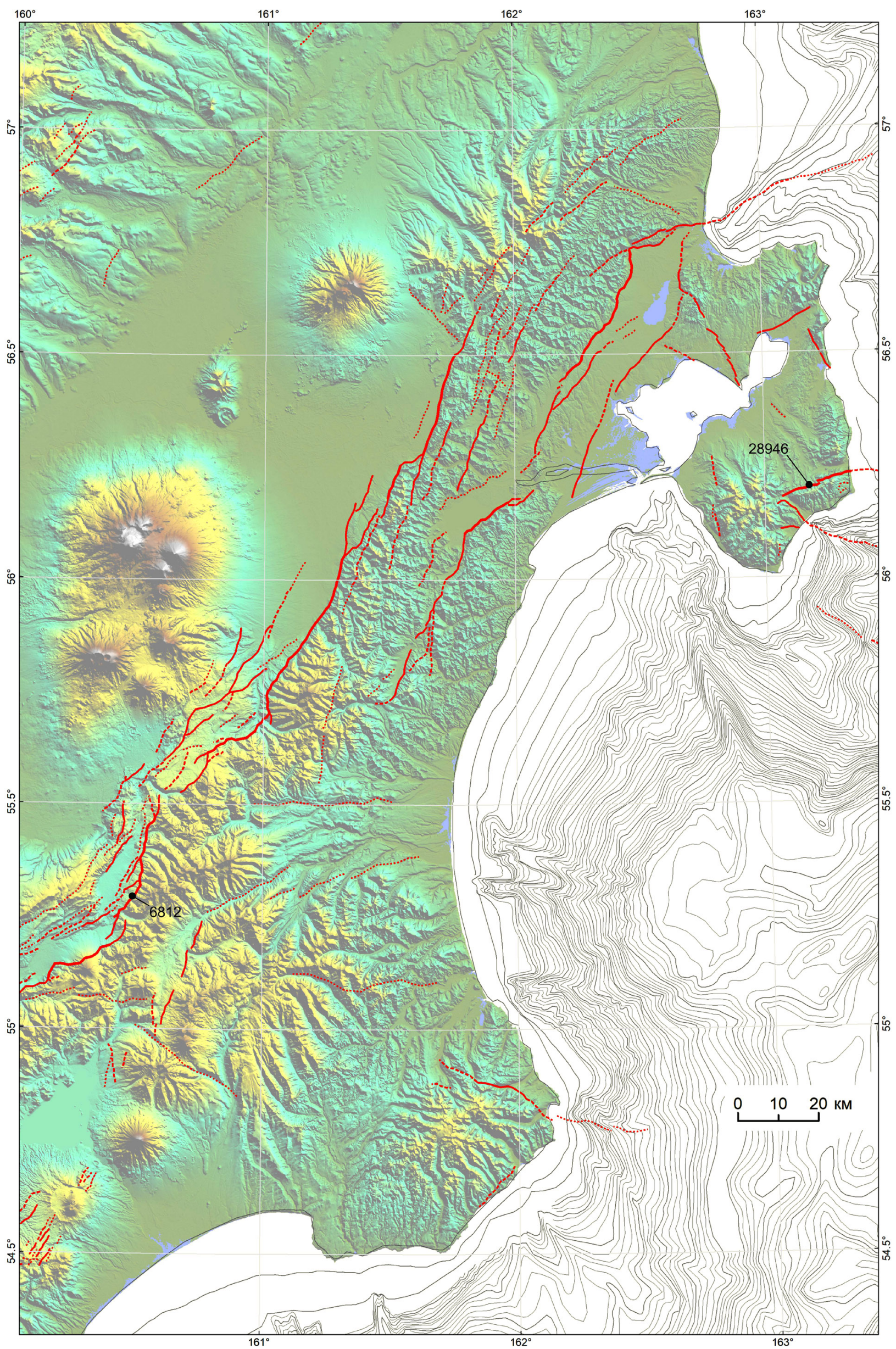


Рис. 5. Визуализация Базы данных об активных разломах Евразии: карта разломов части Центральной Камчатки.

1-5 - то же, что на рис. 1; 6 - разломы с рангом скорости 3 и достоверностью активности D. Точки с вынесенными цифрами разломы, представленные в таблице. Изображение рельефа в пределах суши по [Jarvis et al., 2008]. Изображение рельефа дна в пределах акватории по [Seliverstov, 2009].

Fig. 5. Visualization of the Active Faults of Eurasia Database: a simplified fault map showing a segment of Central Kamchatka.

1-5 - same as in Fig. 1; 6 - faults characterized by displacement rate 3 and reliability D. The faults listed in the table are marked by circles with numbers. The relief of the land area is given after [Jarvis et al., 2008]. The relief of the sea bottom areas is given after [Seliverstov, 2009].

с указанием лишь вертикальной компоненты движения.

Ранг скорости движения. Поскольку наличие позднечетвертичных движений обусловливает само включение структуры в БД, атрибут RATE является обязательным и ему должно быть присвоено определенное значение, даже если оно оценивается по косвенным признакам. Значение атрибута RATE формируется не только на основании конкретных данных о скоростях перемещения по разломам, но и с учетом всех признаков, отражающих интенсивность деформаций. Значения атрибута RATE характеризуют скорости перемещения крыльев активных структур и разделены на три градации: $<1$ мм/год, 1-5 мм/год и >5 мм/год, которые обозначены индексами 3,2 и 1, соответственно. Однако в материалах-источниках лишь малая доля структур обеспечена достоверными значениями скорости перемещения по результатам полевых измерений, и эти измерения относятся лишь к отдельным участкам разломных зон, поэтому, особенно при недостатке точных данных, оценка атрибута RATE основывается на анализе структурной позиции объекта во включающей его разломной зоне. Например, участку разломной зоны может быть присвоено повышенное по сравнению с соседними значение атрибута RATE, если он образован слиянием нескольких нарушений в единый магистральный разлом.

Таким образом, атрибут RATE отражает как скорость взаимного перемещения крыльев разлома, т.е. элементов, внешних по отношению к соответствующему объекту, так и степень концентрации деформаций в пределах объекта как элемента зоны нарушений. В последнем случае под атрибутом RATE понимается скорее ранг объекта в общей системе нарушений, оцениваемый с учетом фонового уровня активности региона и насыщенности территории активными разломами. Тем не менее мы полагаем, что атрибут RATE чаще всего отражает реальные скорости движений; например, объект со значением атрибута RATE=1 действительно имеет скорость перемещения >5 мм/год.
Индексы в оценочном атрибуте RATE не всегда соответствуют значениям скоростей движений, приводимым в атрибутах PARM и TEXT со ссылками на источники сведений и определенным полевыми наблюдениями в отдельных частях разломов. Происходит это в следующих случаях: (1) в обосновывающих атрибутах сведения из разных источников различаются, образуя диапазон оценок сопоставимой достоверности; (2) протяженный разлом разделен на несколько объектов БД, и указанные в источнике характеристики зоны отнесены лишь к самым достоверным из них; (3) указанная в источнике скорость представляется сомнительной в контексте комплекса смежных структур. В этих случаях атрибут RATE оценивается, исходя из структурной позиции объекта.

В виде целостного объекта БД крупное тектоническое нарушение может быть представлено лишь при его рассмотрении на определенном уровне генерализации. По мере детализации рассмотрения разлом может оказаться выраженным серией отдельных нарушений, т.е. разломной зоной, включающей и пластические деформации, в которых реализуется некоторая доля общего смещения крыльев. Присвоение объекту БД, отвечающему такой зоне, характеристик, замеренных на частном элементе ее внутреннего строения, не всегда оправдано. Общая скорость перемещений по зоне разломов может быть выше за счет неучтенных смещений по параллельным и оперяющим ветвям и за счет пластической составляющей деформации. С другой стороны, высокая скорость по одной из ветвей зоны не является основанием для ее присвоения другим разломам той же зоны, что привело бы к неоправданному завышению ее оценки для всей структуры.

Протяженные структуры разделяются в БД на серии объектов, и указанное в материалах-источниках значение скорости оставляется лишь для тех из них, которые по своей выраженности на контекстных материалах и уже накопленным в БД сведениям с наибольшей вероятностью отвечают этому значению. При рассмотрении крупной и 

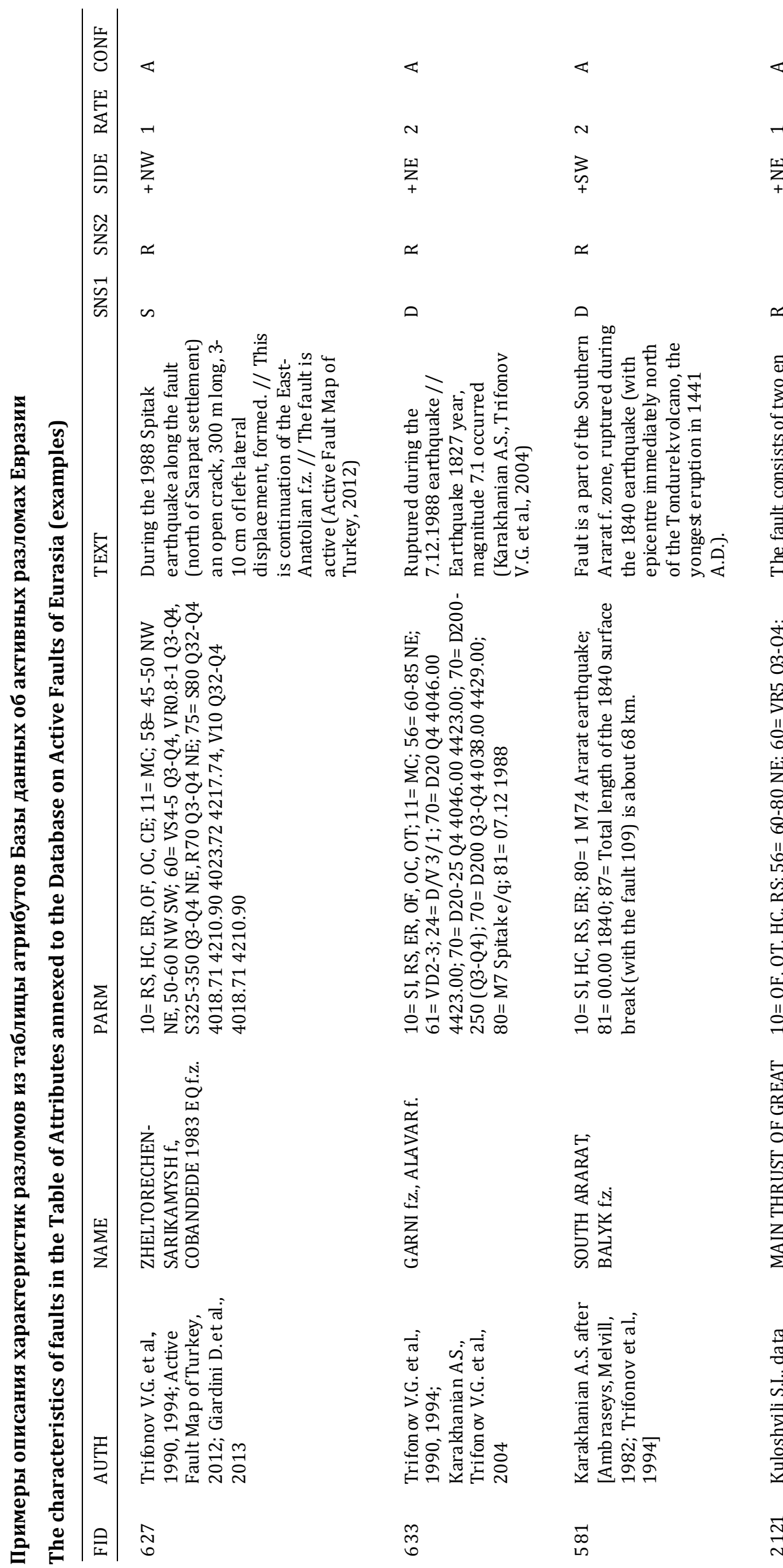

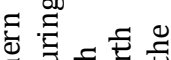

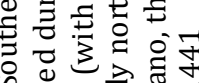

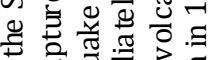

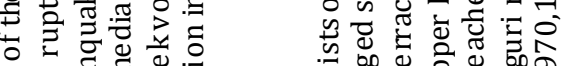

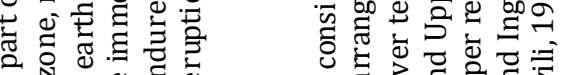

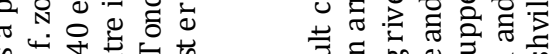

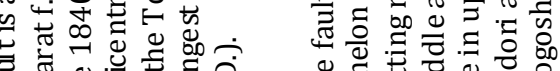

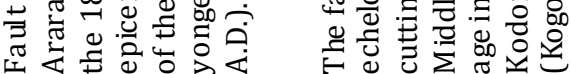

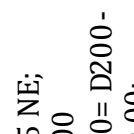

녕요이

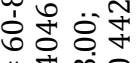

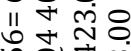

ن용ㅇㅇ

II II

正产方令

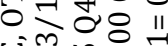

Uئ

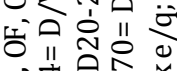

密劣

w

ำ

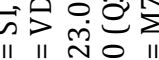

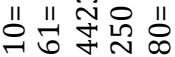

它苋

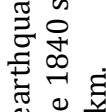

焉焉

究

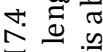

$\sum_{-1} \frac{\pi}{0} \frac{9}{0}$

$0_{\infty}$

我市

ज車吉

ज宊

i:

$\underset{+}{y_{+}}$

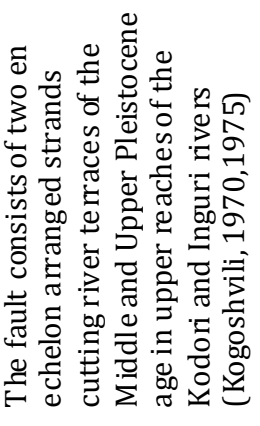

宅

ชิก

นิ

잉

凷

$\infty \sum^{0}$

$8 \|_{\infty} \stackrel{2}{0}$

눙셩

$\approx$

노용

ثㅇㅎㅇ.

不京重

Iㅣ임

잉송

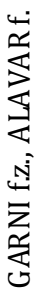

突

究

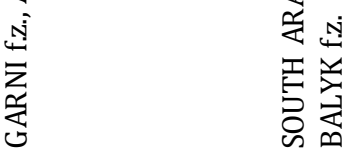

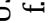

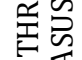

廵

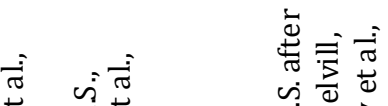

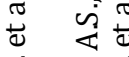

نे.

ठठ

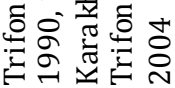

i

.ี จิ

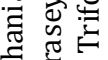

त्ते है त्ञ

$\Sigma U$

$\underset{m}{m}$

$\underset{\infty}{\infty}$

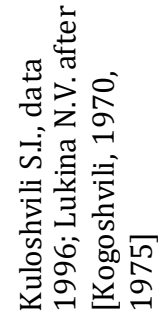

$\stackrel{\text { ㄱ }}{\text { ป }}$ 


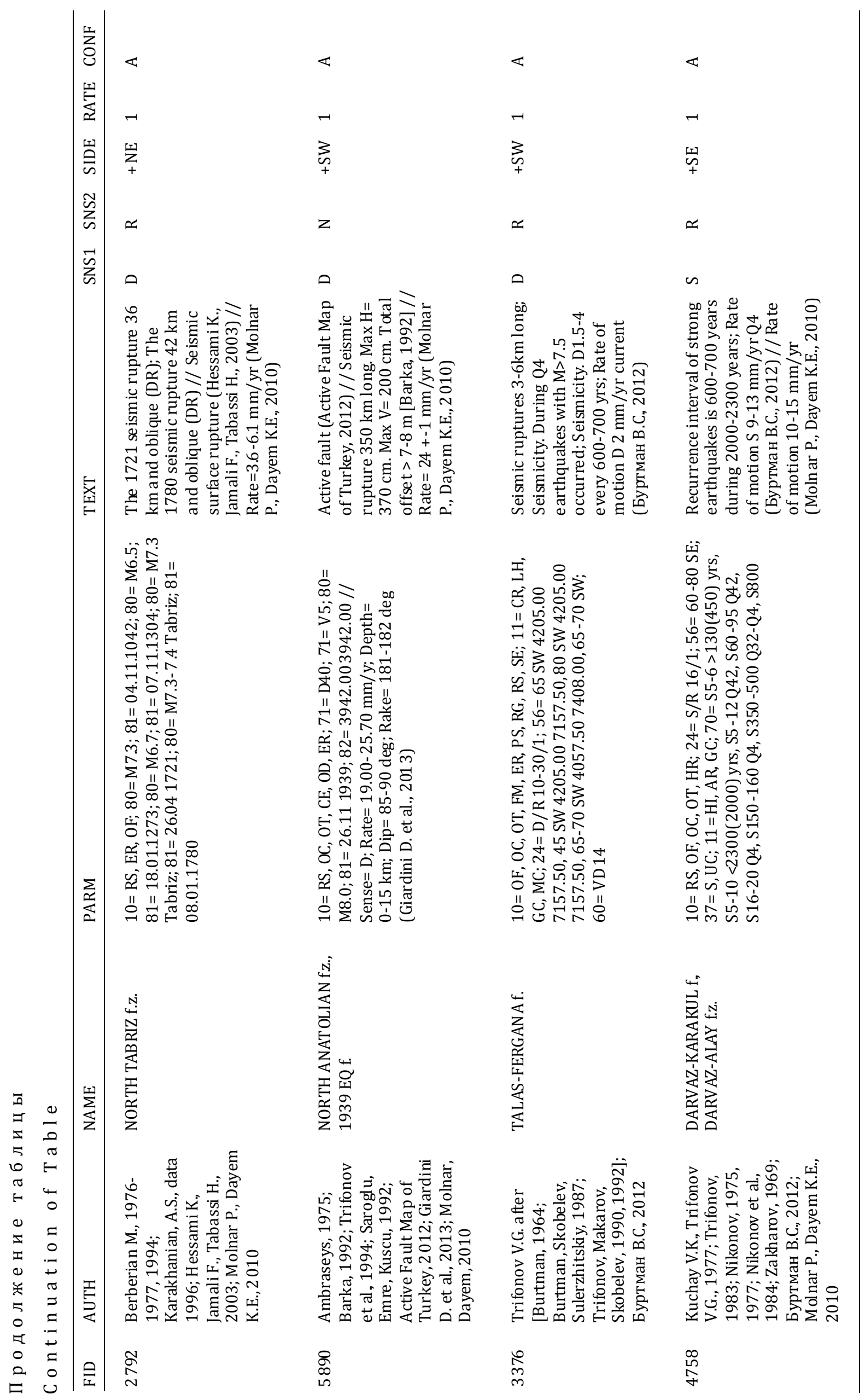




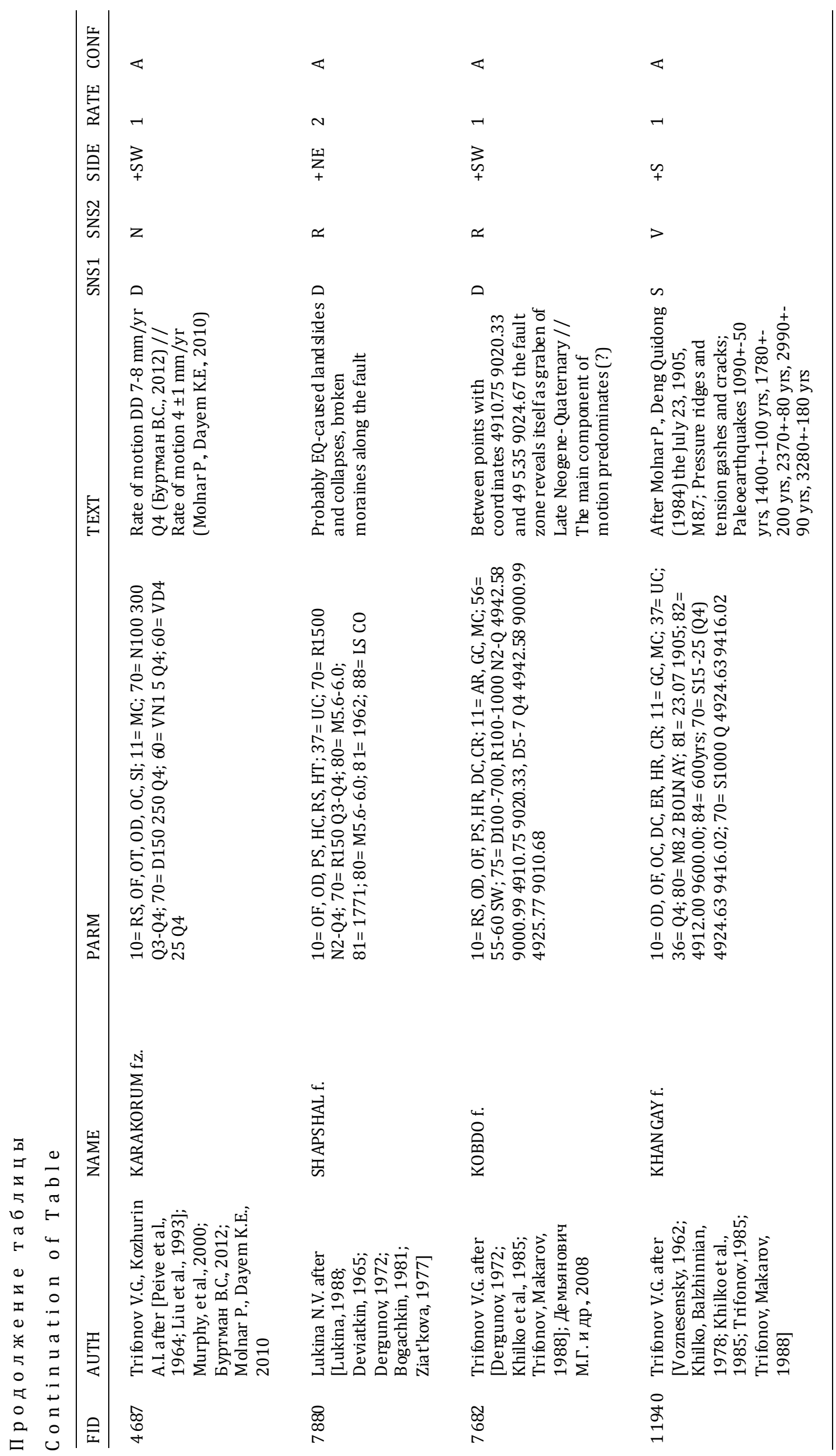




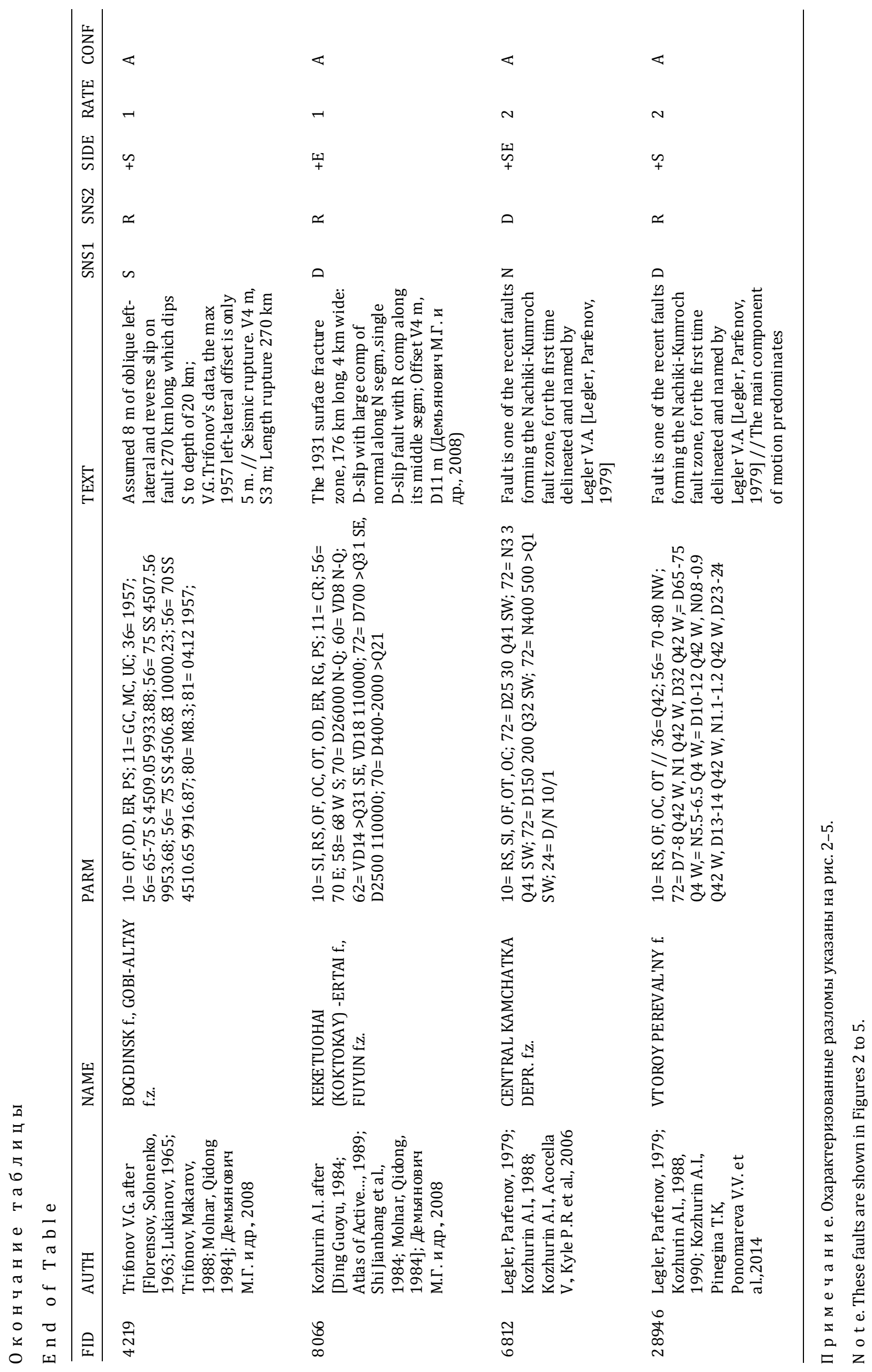


протяженной разломной зоны, которая в рабочем масштабе БД представлена сочетанием объектов с разными значениями атрибута RATE, характеристика зоны как целостной структуры будет определяться значениями атрибута RATE тех ее участков, где эти значения наивысшие. При прочих равных условиях максимальные значения скорости присваиваются участкам, расположенным в центре зоны или образованным слиянием нескольких ее ветвей. Если в материале-источнике приведены достоверные и точные данные о скоростях на всех участках и ветвях структуры, то предпочтение отдается результатам конкретных наблюдений и атрибут RATE объекта оценивается по этим значениям. Для достоверно активных разломов, если высокие скорости движения по ним определены лишь в допозднеплейстоценовое время (например, с раннего плейстоцена), эти же значения с большой вероятностью могут быть присвоены и позднеплейстоцен-голоценовым движениям.

Достоверность активности. Атрибут достоверности CONF определяет саму возможность внесения объекта в БД. Это наиболее типичный оценочный атрибут, значение которого определяется составителями БД на основе анализа конкретных сведений материалов-источников о возрасте последних движений по разлому с учетом всего комплекса данных об объекте и его структурно-кинематической позиции. Атрибут CONF отражает обоснованность позднеплейстоцен-голоценовых движений по разлому, одним из критериев которой является степень его изученности. По обоснованности позднечетвертичной активности разломы разделяют обычно на достоверные и предполагаемые. Столь категоричное разделение часто оказывается субъективным, поскольку приводимые авторами доказательства активности основываются на разных подходах. Оценка нарушения как активного может иметь разную степень гипотетичности в зависимости от используемых сведений и особенностей региона, поэтому для обеспечения сопоставимости оценок на территориях с разным тектоническим режимом и разной степенью изученности, расширения возможностей использования материала БД при выявлении унаследованности активных разломов от новейших нарушений и оценке сейсмической опасности шкала оценки достоверности объектов БД детализирована. По степени достоверности признаков активности объекты БД разделены на четыре категории: A, B, C и D.

Отнесение объекта к категории А означает, что выявлены сразу несколько независимых явных признаков активности, а сама активная структура хорошо изучена с точки зрения ее кинематики и внутреннего строения. Основанием для включения объекта в эту категорию являются установленные в поле или четко выраженные на детальных дистанционных материалах деформации молодых форм рельефа и датированные смещения позднеплейстоцен-голоценовых отложений, а также произошедшие в зоне разлома сильные землетрясения или палеоземлетрясения.

Включение объекта в категорию В требует проявления каких-либо из указанных выше признаков активности, однако допускается их меньшая выраженность. В частности, могут быть достаточными признаки молодых смещений на дистанционных материалах.

Объекты включаются в категорию С, когда перечисленные выше признаки активности или хотя бы один из них присутствуют, но все они выражены нечетко, проявлены не вполне убедительно, определены неточно или могут иметь различные интерпретации, тогда как плиоцен-четвертичные смещения по разлому несомненны.

К категории D отнесены объекты с проявлениями плиоцен-четвертичных движений, по которым признаки молодых смещений пока не найдены. Чаще всего это элементы новейших разломных зон, недостаточно изученные на предмет позднечетвертичной активности. Вместе с тем косвенные признаки дают основание полагать, что следы такой активности могут быть обнаружены при более детальном целенаправленном изучении. Косвенными признаками могут служить характерная выраженность нарушения на дистанционных материалах, приуроченность эпицентров землетрясений, а также закономерная структурно-кинематическая позиция разлома по отношению к смежным достоверно активным структурам, придающая их системе большую структурно-кинематическую целостность. Объекты категории D не могут переходить в более высокие категории достоверности, пока не получат конкретного обоснования своей активности.

Наиболее надежным критерием оценки атрибута CONF служит наличие в материале-источнике точных полевых данных о смещениях и деформациях позднеплейстоцен-голоценовых отложений, форм рельефа и антропогенных сооружений. Если такие фактические данные существуют, они вносятся в обосновывающие атрибуты и объект БД однозначно относится к категории достоверности A.

Второй по значимости критерий оценки достоверности - это характер и степень выраженности объекта на детальных моделях рельефа, космических изображениях и аэрофотоснимках. Современные дистанционные материалы обладают достаточно высоким разрешением, чтобы по комплексу дешифровочных признаков идентифицировать объект в качестве активного разлома, а иногда и 
оценить его кинематику. Только результатов дешифрирования обычно недостаточно для присвоения объекту высшей достоверности, однако оно может быть полезным в сочетании с менее надежными данными о смещениях и сейсмичности для обоснования категории В.

Остальные четыре критерия оценки достоверности менее надежны, являются косвенными и потому не могут служить основой для обоснования высших значений оценки достоверности. Однако они учитываются, особенно при оценке предполагаемой активности объектов категорий C и D.

Третий критерий - приуроченность к плоскости разлома гипоцентров землетрясений, особенно если они неглубокие. В регионах с низкими скоростями деформаций этот критерий может быть ненадежен. Однако наличие закономерной связи землетрясений с линией разлома с учетом ожидаемого угла падения сместителя является серьезным доводом считать его активным.

Четвертый критерий - позиция объекта относительно окружающих активных разломов. Структурно-кинематические соотношения смежных элементов в целостной системе нарушений накладывают ограничения на возможные значения параметров объектов. В зависимости от того, соответствуют ли этим ограничениям указанные в материалах-источниках параметры, достоверность объекта БД повышается или понижается. Если объект, согласно его кинематике и выраженности в контекстных материалах, занимает закономерное место в структуре уже установленных активных разломов, то это повышает оценку его достоверности.

Пятый критерий - согласованность мнений исследователей об активности разлома, а также количество независимых публикаций, в которых объект указывается как активный. Каждый новый исследователь производит переоценку результатов предшественников на основе собственного опыта и всего комплекса новых сведений, технологий, методов и концепций, видит старый объект в новых аспектах и вносит в его обоснование дополнительные аргументы. Однако сама по себе множественность ссылок не может служить надежным обоснованием достоверности объекта, поскольку разные исследователи могут опираться на одни и те же старые первичные данные, не внося существенных дополнений. Возможны случаи, когда на некотором участке разлома разные авторы картируют его поразному. Если по результатам дешифрирования оба варианта выглядят убедительно, то в БД на таком участке приводятся оба варианта, каждый под своим авторством. Оценка достоверности в пределах согласованной интерпретации будет выше, чем на участке, о котором мнения разных авторов расходятся.
Наконец, шестой критерий оценки достоверности объектов обобщенно определяется комплексом показателей, включающим общее количество и многосторонность приведенной информации об объекте, степень заполненности всех атрибутов, количество формализованных параметров. При всей условности, этот критерий служит отражением общего уровня внимания исследователей к рассматриваемому объекту, детальности и многосторонности его изучения, что косвенно повышает оценку его достоверности.

Таким образом, на оценку достоверности влияет вся совокупность содержания обосновывающих атрибутов.

Некоторые исследователи платформенных областей делали попытки выделения активных нарушений лишь по результатам дешифрирования дистанционных материалов. При обнаружении признаков молодых движений на ограниченном участке дешифрируемого элемента авторы часто стремились неоправданно экстраполировать результат на всю длину разлома. Это заставляет относиться к таким результатам с большой осторожностью. Как бы ни назывались эти элементы в материалах-источниках, они или их фрагменты могут быть включены в БД лишь при наличии хотя бы косвенных данных в пользу их активности. Процессы платформенного тектогенеза происходят медленно, а их проявления слабы и рассеяны, что крайне редко приводит к появлению тех признаков, по которым нарушение можно интерпретировать как активное. Однако распределение на периферии платформ коровой сейсмичности в комплексе с другими данными позволяет выделять линейные зоны, с которыми, предположительно, связываются косвенные признаки позднечетвертичных движений. До накопления более обоснованных сведений об активности таких зон они включаются в БД в качестве объектов категории D. Исключением являются платформенные территории, где проявления активной тектоники усиливаются процессами гляциоизостазии, например в Фенноскандии.

Важная задача составителей БД при включении в нее новых материалов состоит в согласовании значений оценочных атрибутов объектов с уже имевшимися в БД. Это согласование и, если требуется, переоценка атрибутов происходят с учетом обоснованности объектов, в том числе путем анализа их структурно-кинематических соотношений на участке рассмотрения в рабочем масштабе. В качестве средства перераспределения значимости отдельных разломов в общей системе объектов БД используется атрибут достоверности активности CONF и отчасти атрибут RATE, характеризующий скорость тектонических движений. 
При последовательном применении к разнородным исходным материалам одинаковых методических принципов их обработки в процессе регулярной переоценки уже имеющихся данных в соответствии с непрерывно поступающими новыми сведениями происходит постепенное совершенствование тектонической модели, представленной в форме БД. Ее реалистичность возрастает в процессе последовательной интеграции разных данных и экспертных мнений с постепенным отказом путем снижения оценки достоверности от тех из них, которые менее всего согласуются с новыми достоверными сведениями. Таким образом, БД является не только совокупностью установленных фактов, но и формой интеграции высказанных на их основе экспертных мнений. Примеры итоговой атрибутики активных разломов приведены в таблице.

\section{4. ЗАКЛЮЧЕНИЕ}

Представляемая новая база данных об активных разломах Евразии (БД) интегрировала в едином ключе большой объем существующих на 2017 г. сведений об активных разломах и связанных с ними структурных формах с признаками последних перемещений в позднем плейстоцене и голоцене. Этот материал (более 20 тыс. объектов) единообразно форматирован и снабжен географической привязкой объектов, приведенных к одинаковому масштабу. Рабочий масштаб, в котором составлялась БД, - 1:500000, а базовый демонстрационный масштаб - 1:1000000. База данных, методика составления которой изложена выше, построена таким образом, что каждый ее объект снабжен двумя видами характеристик (атрибутов) - обосновывающими и оценочными. Обосновывающие атрибуты содержат определенным образом форматированные сведения об активных разломах, зонах разломов и других активных структурах - их названия, данные о морфологии и кинематике (направлении перемещений), амплитуды смещений за разные отрезки времени и рассчитанные по ним скорости движений, возраст последних признаков активности, проявления сейсмичности и палеосейсмично- сти, соотношения активных структур с параметрами коровых землетрясений и другие характеристики, представленные в текстовом виде, а также сведения об источниках информации. Оценочные атрибуты - это система символов (индексов), отражающих важнейшие параметры активных структур - их кинематику в рамках принятой в структурной геологии типизации, ранг скорости позднечетвертичных движений (три градации) и степень достоверности выделения структуры в качестве активной, т.е. обоснованности самого факта позднеплейстоцен-голоценовых подвижек (четыре градации). Эти индексы позволяют легко сопоставлять объекты по любому из атрибутов компьютерным способом между собой и с любыми другими видами оцифрованной информации.

Итак, БД предоставляет удобную возможность как для извлечения конкретных сведений об отдельных разломах и их проявлениях на разных территориях, так и для решения более общих задач - тематического картографирования, определения интенсивности и параметров проявления современных геодинамических процессов, оценки сейсмической и других геодинамических опасностей территорий, тектонического районирования и выявления тенденций тектонического развития на последнем, плиоцен-четвертичном, этапе развития Земли. Таким образом, БД является существенным вкладом в исследование тектонических процессов и обеспечение безопасности России и других стран Евразии от природных бедствий геодинамического происхождения. Формат построения БД допускает ее постоянное пополнение и коррекцию с появлением новых сведений об активной тектонике. БД снабжена кратким гидом для пользователя и полным списком опубликованной литературы и других источников, использованных для ее составления. Этот список будет пополняться по мере пополнения и уточнения БД.

\section{5. БЛАГОДАРНОСТИ}

Работа выполнена за счет средств Российского научного фонда, проект № 17-17-01073.

\section{6. ЛИТЕРАTУРA / REFERENCES}

Basili R., Kastelic V., Demircioglu M.B., Garcia Moreno D., Nemser E.S., Petricca P., Sboras S.P., Besana-Ostman G.M., Cabral J., Camelbeeck T., Caputo R., Danciu L., Domac H., Fonseca J., García-Mayordomo J., Giardini D., Glavatovic B., Gulen L., Ince Y., Pavlides S., Sesetyan K., Tarabusi G., Tiberti M.M., Utkucu M., Valensise G., Vanneste K., Vilanova S., Wössner J., 2013. The European Database of Seismogenic Faults (EDSF) compiled in the framework of the Project SHARE. Available from: http://diss.rm.ingv.it/share-edsf/ (last accessed October 29, 2017). https://doi.org/10.6092/ INGV.IT-SHARE-EDSF.

Distribution of Active Faults and Trenches in the Philippines, 2008. Philippine Institute of Volcanology and Seismology (PHIVOLCS). Department of Science and Technology. Available from: http://www.phivolcs.dost.gov.ph (last accessed October 29, 2017). 
Emre Ö., Duman T.Y., Özalp S., Elmacı H., Olgun Ş., Şaroğlu F., 2013. Active Fault Map of Turkey with and Explanatory Text. General Directorate of Mineral Research and Exploration, Special Publication Series-30. Ankara, Turkey. Available from: http://www.mta.gov.tr/eng/maps/active-fault-1250000. (last accessed October 29, 2017).

Galadini F., Meletti C., Vittori E., 2001. Major active faults in Italy: available surficial data. Netherlands Journal of Geosciences 80 (3-4), 273-296. https://doi.org/10.1017/S001677460002388X.

García-Mayordomo J., Insua-Arévalo J.M., Martínez-Díaz J.J., Jiménez-Díaz A., Martín-Banda R., Martín-Alfageme S., Álvarez-Gómez J.A., Rodríguez-Peces M., Pérez-López R., Rodríguez-Pascua M.A., Masana E., Perea H., Martín-González F., Giner-Robles J., Nemser E.S., Cabral J., QAFI compilers, 2012. The Quaternary Active Faults Database of Iberia (QAFI v.2.0). Journal of Iberian Geology 38 (1), 285-302. https://doi.org/10.5209/rev_JIGE.2012.v38.n1.39219.

Hessami Kh., Jamali F., Tabassi H. (Eds.), 2003. Major Active Faults of Iran, Scale 1:2500000. Ministry of Science, Research and Technology. International Institute of Earthquake Engineering and Seismology (IIEES), Tehran, Iran.

Jarvis A., Reuter H.I., Nelson A., Guevara E., 2008. Hole-filled SRTM for the globe Version 4, available from the CGIAR-CSI SRTM 90m Database. Available from: http://srtm.csi.cgiar.org (last accessed November 17, 2017).

Jomard H., Cushing E.M., Palumbo L., Baize S., David C., Chartier T., 2017. Transposing an active fault database into a seismic hazard fault model for nuclear facilities - Part 1: Building a database of potentially active faults (BDFA) for metropolitan France. Natural Hazards and Earth System Sciences 17 (9), 1573-1584. https://doi.org/10.5194/ nhess-17-1573-2017.

Kosuwan S., Takashima I., Charusiri P., 2006. Active Fault Map in Thailand. Department of Mineral Resources. Thailand.

Kozhurin A.I., 2004. Active faulting at the Eurasian, North American and Pacific plates junction. Tectonophysics 380 (3-4), 273-285. https://doi.org/10.1016/j.tecto.2003.09.024.

Kozhurin A.I., 2013. Active Tectonics of the Northwestern Sector of the Pacific Tectonic Belt (According to the Study of Active Faults). PhD Brief Thesis (Doctor of Geology and Mineralogy). GIN RAS, Moscow, 46 p. (in Russian) [Кожyрин А.И. Активная тектоника северо-западного сектора Тихоокеанского тектонического пояса (по данным изучения активных разломов): Автореф. дис. ... докт. геол.-мин. наук. М.: ГИН РАН, 2013. 46 с.].

Kozhurin A.I., Ponomareva V.V., Pinegina T.K., 2008. Active faulting in the south of Central Kamchatka. Bulletin of Kamchatka Regional Association Educational-Scientific Center. Earth Sciences (2), 10-27 (in Russian) [Кожурин А.И., Пономарева В.В., Пинегина Т.К. Активная разломная тектоника юга Центральной Камчатки // Вестник КРАУНЦ. Науки о Земле. 2008. № 2. С. 10-27].

Lunina O.V. 2016. The digital map of the Pliocene-Quaternary crustal faults in the southern East Siberia and the adjacent Northern Mongolia. Geodynamics \& Tectonophysics 7 (3), 407-434 (in Russian) [Лунина О.В. Цифровая карта разломов для плиоцен-четвертичного этапа развития земной коры юга Восточной Сибири и сопредельной территории Северной Монголии // Геодинамика и тектонофизика. 2016. Т. 7. № 3. С. 407-434]. https:// doi.org/10.5800/GT-2016-7-3-0215.

McCalpin J.P. (Ed.), 1996. Paleoseismology. Academic Press, New York, 588 p.

National Research Council, 1986. Active Tectonics: Impact on Society. National Academy Press, Washington D.C., 266 p. https://doi.org/10.17226/624.

Ruleman C.A., Crone A.J., Machette M.N., Haller K.M., Rukstales K.S., 2007. Map and Database of Probable and Possible Quaternary Faults in Afghanistan. U.S. Geological Survey Open-File Report 2007-1103. U.S. Geological Survey, 39 p.

Seliverstov N.I., 2009. Geodynamics of the Conjugation Zone of the Kuril-Kamchatka and Aleutian Island Arcs. Publishing House of the V. Bering Kamchatka State University, Petropavlovsk-Kamchatsky, 191 p. (in Russian) [Селиверстов Н.И. Геодинамика зоны сочленения Курило-Камчатской и Алеутской островных дуг. Петропавловск-Камчатский: Изд-во КамГУ им. В. Беринга, 2009. 191 с.].

Sieh K.E., 1978. Prehistoric large earthquakes by slip on the San Andreas Fault at Pallett Creek, California. Journal of Geophysical Research: Solid Earth 83 (B8), 3907-3939. https://doi.org/10.1029/JB083iB08p03907.

Taylor M., Yin A., 2009. Active structures of the Himalayan-Tibetan orogen and their relationships to earthquake distribution, contemporary strain field, and Cenozoic volcanism. Geosphere 5 (3), 199-214. https://doi.org/10.1130/ GES00217.1.

Trifonov V.G., 1983. Late Quaternary Tectogenesis. Nauka, Moscow, 224 p. (in Russian) [Трифонов В.Г. Позднечетвертичный тектогенез. М.: Наука, 1983. 224 с.].

Trifonov V.G., 1985. Features of the development of active faults. Geotektonika (Geotectonics) (2), 16-26 (in Russian) [Трифонов В.Г. Особенности развития активных разломов // Геотектоника. 1985. № 2. C. 16-26.

Trifonov V.G., 1997. World map of active faults, their seismic and environmental effects. In: D. Giardini, S. Balassanian (Eds.), Historical and prehistorical earthquakes in the Caucasus. Kluwer, Dordrecht, p. 169-180.

Trifonov V.G., 2004. Active faults in Eurasia: general remarks. Tectonophysics 380 (3-4), 123-130. https://doi.org/ 10.1016/j.tecto.2003.09.017.

Trifonov V.G., Ammar O. (Eds.), 2012. Neotectonics, Recent Geodynamics and Seismic Hazard of Syria. GEOS, Moscow, 216 p. (in Russian) [Неотектоника, современная геодинамика и сейсмическая опасность Сирии / Ред. В.Г. Трифонов. М.: ГЕОС, 2012. 216 с.].

Trifonov V.G., Bayractutan M.S., Karakhanian A.S., Ivanova T.P., 1993. The Erzincan earthquake of 13 March 1992 in Eastern Turkey: tectonic aspects. Terra Nova 5 (2), 184-189. https://doi.org/10.1111/j.1365-3121.1993.tb00244.x. 
Trifonov V.G., Kozhurin A.I., 2010. Study of active faults: Theoretical and applied implications. Geotectonics 44 (6), 510-528. https://doi.org/10.1134/S0016852110060051.

Trifonov V.G., Machette M.N., 1993. The World Map of Major Active Faults Project. Annali di Geofisica 36 (3-4), 225-236.

Trifonov V.G., Soboleva O.V., Trifonov R.V., Vostrikov G.A., 2002. Recent Geodynamics of the Alpine-Himalayan Collision Belt. GEOS, Moscow, 225 p. (in Russian) [Трифонов В.Г., Соболева О.В., Трифонов Р.В., Востриков Г.А. Современная геодинамика Альпийско-Гималайского коллизионного пояса. М.: ГЕОС, 2002. 225 с.].

Ulomov V.I., Shumilina L.S., 1999. The Set of General Seismic Zonation Maps of the Russian Federation - OSR-97. Scale 1:8000000. Explanatory Note. UIPE RAS, Moscow, 57 p. (in Russian) [Уломов В.И., Шумилина Л.С. Комплект карт общего сейсмического районирования территории Российской Федерации - ОСР-97. Масштаб 1:8000000. Объяснительная записка. М.: ОИФЗ РАН, 1999. 57 с.].

Wallace R.E., 1968. Notes on stream channels offset by the San Andreas Fault, southern Coast Ranges, California. In: W.R. Dickinson, A. Grantz (Eds.), Proceedings of the conference on geologic problems of the San Andreas fault system. Stanford University Publications in Geological Sciences, vol. 11, p. 6-21.

Yeats R.S., Sieh K., Allen C.R., 1997. The Geology of Earthquakes. Oxford University Press, New York - Oxford, 568 p.

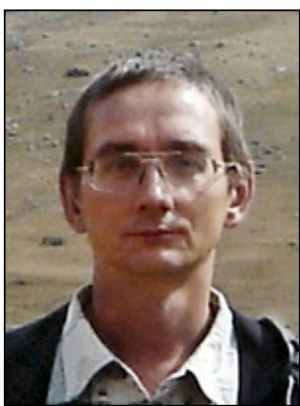

Бачманов Дмитрий Михайлович, канд. геол.-мин. наук, с.н.с.

Геологический институт РАН

119017, Москва, Пыжевский пер., 7, Россия

凶 e-mail:dmbv@mail.ru

Bachmanov, Dmitry M., Candidate of Geology and Mineralogy, Senior Researcher

Geological Institute of RAS

7 Pyzhevsky lane, Moscow 119017, Russia

$\triangle$ e-mail:dmbv@mail.ru

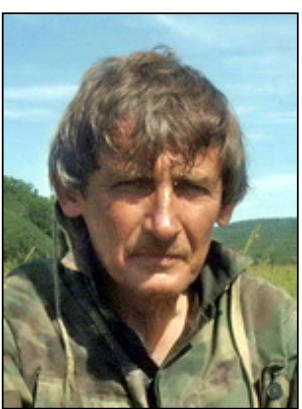

Кожурин Андрей Иванович, докт. геол.-мин. наук, зав. лабораторией

Геологический институт РАН

119017, Москва, Пыжевский пер., 7, Россия

Институт вулканологии и сейсмологии ДВО РАН

683006, Петропавловск-Камчатский, бульвар Пийпа, 9, Россия

e-mail: anivko@yandex.ru

Kozhurin, Andrei I., Doctor of Geology and Mineralogy, Head of Laboratory

Geological Institute of RAS

7 Pyzhevsky lane, Moscow 119017, Russia

Institute of Volcanology and Seismology, Far East Branch of RAS

9 Piip Boulevard, Petropavlovsk-Kamchatsky 683006, Russia e-mail: anivko@yandex.ru

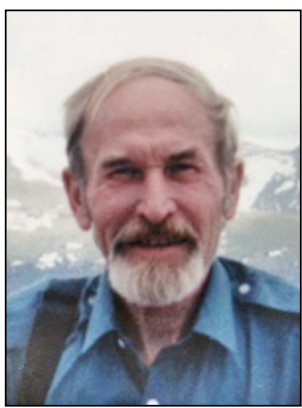

Трифонов Владимир Георгиевич, докт. геол.-мин. наук, профессор, с.н.с.

Геологический институт РАН

119017, Москва, Пыжевский пер., 7, Россия

e-mail: trifonov@ginras.ru

Trifonov, Vladimir G., Doctor of Geology and Mineralogy, Senior Researcher

Geological Institute of RAS

7 Pyzhevsky lane, Moscow 119017, Russia

e-mail: trifonov@ginras.ru 